\title{
Análise do impacto da morfologia urbana na demanda estimada de energia das edificações: um estudo de caso na cidade de Maceió, AL
}

\author{
Evaluation of the impact of urban morphology on the \\ estimated energy demand of buildings: a case study in \\ Maceió, Brazil
}

\section{Tathiane Agra de Lemos Martins Marion Bonhomme Luc Adolphe}

\section{Resumo}

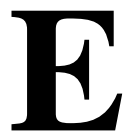

ste estudo apresenta um método simplificado de análise e mapeamento morfológico do tecido urbano para auxiliar no estudo da climatologia e do impacto da forma urbana na demanda de energia das edificações. Diferentes parâmetros foram empregados na análise da geometria urbana, a fim realizar uma cartografia de áreas morfologicamente homogêneas, cada uma apresentando uma influência diferente na demanda energética das edificações. Numa primeira etapa, os parâmetros morfológicos urbanos foram automatizados e calculados em um sistema de informação geográfica, para diferentes resoluções espaciais. Os resultados morfológicos obtidos para uma aplicação na cidade de Maceió, AL, foram analisados por meio da Análise de Componentes Principais (ACP), a partir da qual foi possível identificar a significância dos parâmetros para o contexto urbano considerado. A análise de agrupamento (Clustering Analysis) permitiu que as diferentes configurações tipológicas fossem agregadas, classificadas e, na sequência, submetidas às simulações computacionais para estimativa da demanda de energia das edificações. Seis indicadores morfológicos foram conservados e cinco classes tipológicas representativas do tecido urbano de Maceió foram destacadas. Observou-se um impacto importante na demanda de energia de três parâmetros morfológicos principais: a densidade total construída, a verticalidade, a compacidade e o prospecto médio.

Palavras-chave: Forma urbana. SIG. Clima urbano. Eficiência energética dos edifícios.

\section{Abstract}

This study presents a simplified method of morphological analysis and mapping of the urban fabric to assist in the study of the climatology and impact of the urban

Tathiane Agra de Lemos Martins Universidade Federal do Rio de Janeiro

Rio de Janeiro - RJ - Brasil

Marion Bonhomme Ecole Nationale Supérieure d'Architecture de Toulouse Toulouse - França

Luc Adolphe Institut National des Sciences Appliquées de Toulouse Toulouse - França

Recebido em 19/10/10/12

Aceito em 22/03/13 form on the energy demand of buildings. Different parameters have been applied in the analysis of the urban geometry in order to make a cartography of morphologically homogeneous areas, each one presenting a different type of influence on the energy demand of buildings. In the first stage of the study, the morphological parameters were automated and calculated using a geographical information system software. The morphological results obtained through a case study in Maceió, Alagoas, were analyzed using Principal Components Analysis (PCA), which allowed the identification of the significance of the parameters for the urban context. Through a Clustering Analysis, different typological configurations were grouped, classified and then submitted to computational simulations to estimate the buildings' energy demand. Six morphological indicators were maintained and five typological classes representative of the urban fabric of Maceió were highlighted. The study indicated that three main morphological parameters have a major impact: total built density, verticality, compactness and the mean prospectus.

Keywords: Urban form. GIS. Urban climate. Buildings energy efficiency. 


\section{Introdução}

O dinâmico processo de urbanização associado ao acelerado crescimento populacional afeta os sistemas naturais e construídos em diversas escalas, provocando modificações importantes no clima local e, consequentemente, nos gastos energéticos das cidades e na qualidade de vida dos espaços públicos e privados.

No Brasil, o acelerado processo de urbanização não acompanhou um planejamento urbano adequado na maioria de suas cidades. A ausência de políticas públicas que atuassem no sentido do controle e normalização do uso do solo e das construções urbanas encaminhou as cidades a reproduzir modelos urbanos de baixa qualidade ambiental. Observa-se uma explosão da malha urbana, um processo de verticalização intenso e uso intensivo do solo, bem como a proliferação de assentamentos que desconsideram, sobretudo, as restrições do sítio físico e climático (GOMES; LAMBERTS, 2009).

Por outro lado, nas últimas décadas, a qualidade ambiental dos espaços construídos tem sido cada vez mais abordada nos discursos e colocadas em prática por meio da elaboração de regulamentações voluntárias ou obrigatórias, com vistas a garantir melhor desempenho ambiental das construções. Com a emergência, sobretudo, da problemática energética, essas regulamentações, em diversos países, renovam-se cada vez mais ambiciosas. No entanto, as políticas energéticas, hoje, visam quase exclusivamente às construções, na escala individual, visto que nessa resolução espacial o potencial de ação parece ser mais factível. A abordagem dessa problemática em escala maior, com vistas a integrar dados energéticos ao planejamento urbano e ao projeto arquitetônico situado, é ainda pouco expressiva.

A dificuldade encontra-se em vários aspectos, entre outros:

(a) a carência de estudos quantitativos mais aprofundados sobre o impacto da morfologia da cidade no clima urbano, bem como sobre os efeitos do microclima na demanda de energia para condicionamento artificial dos edifícios urbanos (tais estudos devem, efetivamente, contribuir para a construção de banco de dados de base para dado contexto climático e morfológico);

(b) a ausência de modelos matemáticos mais precisos que abordem os complexos fenômenos físicos em múltiplas escalas simultaneamente; e

(c) poucos estudos prospectivos de modelagem de cenários futuros a partir da evolução da forma urbana existente.
A abordagem dessa problemática deve começar, portanto, com estudos que possam subsidiar a elaboração de instrumentos de intervenção e controle do solo urbano, baseados em indicadores de desempenho e parâmetros que possam responder apropriadamente a cada contexto em favor de uma melhor qualidade ambiental dos espaços construídos.

\section{Indicadores do desempenho ambiental e energético da forma urbana}

Alguns estudos importantes têm sido realizados no sentido de analisar o comportamento ambiental da forma urbana construída a partir do uso de métricas espaciais. Cianco e Ellefsen (1998) realizaram uma classificação morfológica utilizando variáveis que descrevem a ocupação do solo, a morfologia e a orientação dos edifícios. Essa informação calculada empiricamente a partir de mapas, fotos de satélite e imagens aéreas permitiu destacar vários tipos de solo urbano. Da mesma forma, Theurer (1999) propôs uma classificação para estudar a influência dos edifícios sobre a concentração de poluentes. $\mathrm{O}$ autor identificou cada bairro a partir da morfologia de seus edifícios, da distribuição destes no espaço e das formas de ocupação do solo. A maioria dessas análises é resultado de trabalho manual para a construção de banco de dados, formado a partir de diferentes fontes de informação.

Nas últimas duas décadas, foi realizado um progresso significativo na tentativa de medir e analisar padrões espaciais que ajudassem a caracterizar a forma urbana. Embora a aplicação de determinadas métricas espaciais seja uma das metodologias de maior potencial na caracterização da forma urbana, apenas recentemente esses índices têm sido utilizados de modo mais sistemático (ADOLPHE, 2001; HUANG; LUB; SELLERS, 2007; SALAT, 2011).

Cada conjunto de métricas ou indicadores pode variar em função do(s) objetivos(s) e da escala de interesse. É preciso ressaltar que não existe ainda um conjunto definido de indicadores específicos para uso no ordenamento urbano, uma vez que a importância de cada um varia conforme o objetivo e características da paisagem urbana em estudo (HEROLD; COUCLELIS; CLARKE, 2005). Tal sistema de métricas espaciais permitiria, num primeiro momento, repartir os diferentes tecidos urbanos existentes e retirar os traços comuns entre as várias cidades, criando tipos em função de uma 
temática, podendo também constituir um conjunto de ferramentas de auxílio à decisão bastante útil aos urbanistas, pois possuem, muitas vezes, caráter intuitivo, fácil de apreender (SALAT, 2011). Além disso, estudos empíricos têm comprovado o uso de métricas espaciais e do sensoriamento remoto em ambiente urbano como uma prioridade na investigação das cidades (BATTY; LONGLEY, 1994; ALBERTI; WADDELL, 2000).

Nos últimos anos, destacam-se ainda os trabalhos de Rousseaux, Long e Renouard (2011) e Bonhomme, Adolphe e Haddou (2012), ambos na perspectiva da construção de um modelo de evolução urbana. Os modelos propostos buscam descrever cenários morfológicos com o objetivo de antecipar a demanda e a produção de energia em 100 anos, partindo de indicadores e dados existentes de morfologia, economia e meteorologia para cidades na França.

A abordagem da análise e classificação tipomorfológica pode ainda ser bastante útil no estudo do impacto da forma construída em fenômenos climáticos urbanos, como a ilha de calor urbana. Stewart e Oke (2009) sugerem um zoneamento climático local (Local Climate Zone) a partir de modelos genéricos de forma urbana caracterizados por atributos morfoclimáticos (estruturas construídas, superfícies e atividades humanas).

No contexto das pesquisas brasileiras, poucos trabalhos aplicaram métricas espaciais associadas a modelos numéricos nos estudos sobre o impacto da morfologia urbana no clima local. Amorim, Barros Filho e Cruz (2009) propuseram o uso de imagem de satélite para análise da textura urbana, no sentido de destacar padrões morfológicos representativos de áreas urbanas em Recife, PE, a partir de diferentes dinâmicas sociais e urbanas. Lima e Assis (2003) descreveram em SIG um processo para estimar a massa de construção e prever o balanço de energia na cidade de Belo Horizonte, MG. Mendonça e Assis (2003), visando amenizar o impacto da ocupação do solo no clima local, identificaram e registraram características locais, definindo áreas urbanas homogêneas que serviram de base para formular uma hipótese de ventilação urbana local. Souza et al. (2010) avaliaram o papel do fator de visão do céu na intensidade de ilhas de calor em um bairro residencial de Bauru, SP.

Ante o exposto, o presente trabalho apresenta um método simplificado de análise e mapeamento morfológico do tecido urbano para auxiliar na integração do contexto climático ao planejamento urbano, bem como nas avaliações da demanda energética das edificações. Diferentes parâmetros foram empregados na análise da geometria urbana da cidade de Maceió, AL, a fim realizar uma cartografia de áreas morfologicamente homogêneas, cada uma apresentando uma influência diferente na demanda energética das edificações.

\section{Método}

Para alcançar o objetivo proposto, algumas etapas metodológicas foram estabelecidas:

(a) tratamento gráfico de dados vetoriais urbanos e automação de indicadores de desempenho ambiental da forma urbana, com o auxílio das ferramentas do programa ArcMAP/ArcGIS ${ }^{\circledR} \mathrm{e}$ aplicação para a cidade estudo de caso;

(b) análise e tratamento de dados por meio de Análise de Componentes Principais (ACP) e Análise de Agrupamento, para identificação, classificação e cartografia das estruturas urbanas de referência; e

(c) simulação da demanda estimada de energia em edificações urbanas a partir das classes de estruturas urbanas de referência definidas no item b.

\section{Estudo de caso: a cidade de Maceió, Alagoas}

Para a aplicação da metodologia proposta neste trabalho, foi realizado um estudo de caso na cidade de Maceió, AL (Figura 1).

\section{Figura 1 - Posição geográfica da capital alagoana Maceió e o detalhe da área urbana do município}

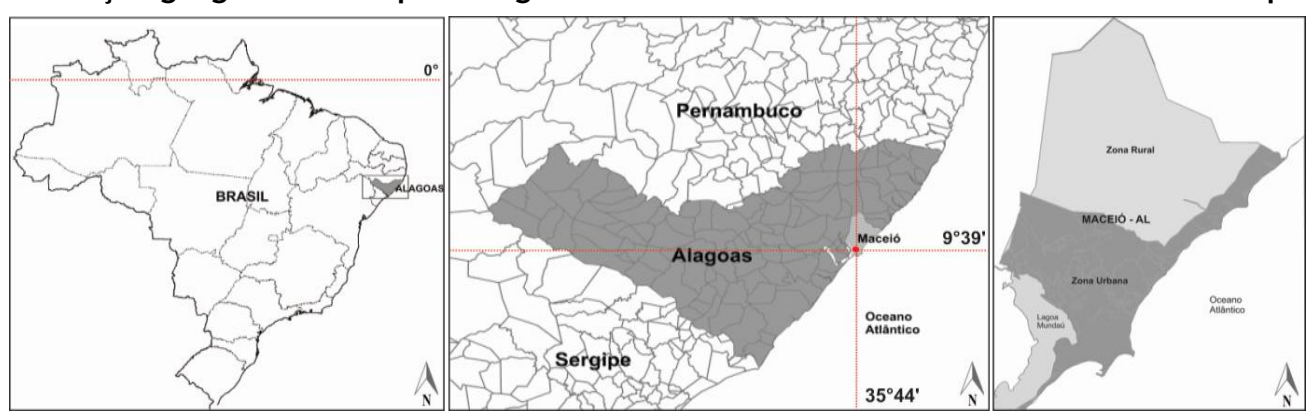

Fonte: Seplande (2012). 
A capital alagoana, situada na região Nordeste do Brasil, a $9^{\circ} 40^{\prime}$ sul e $38^{\circ} 37^{\prime}$ oeste, estende-se por uma área de aproximadamente $500 \mathrm{~km}^{2}$, dos quais $212 \mathrm{~km}^{2}$ compõem sua área urbana. O município conta com 943.110 habitantes, sendo 932.129 de sua crescente população urbana (IBGE, 2010). Desde a metade do século XX, a cidade de Maceió vem acompanhando o crescimento do processo de urbanização como as demais grandes cidades brasileiras, o que resulta em maior demanda por espaços de habitação.

O clima de Maceió é do tipo tropical quente e úmido. Segundo a classificação climática de Köppen, corresponde ao tipo As', caracterizado por reduzidas oscilações térmicas, tanto diárias quanto anuais, e precipitação concentrada, sobretudo nos meses de outono e inverno. A temperatura média anual é de $24,8^{\circ} \mathrm{C}$, e a variação anual é de $2,8^{\circ} \mathrm{C}$ entre os valores médios mensais da temperatura do ar. As temperaturas médias mensais variam entre $22,9^{\circ} \mathrm{C}$ e $27,9^{\circ} \mathrm{C}$ ao longo do ano. Por ser uma cidade litorânea e estar sob a influência de grandes massas d'água, apresenta taxas de umidade relativa do ar com média de $78 \%$. A média pluviométrica anual da cidade é de $2.168 \mathrm{~mm}$, porém apresenta importante variação anual quanto à distribuição de chuvas. Quanto aos ventos incidentes na cidade, estes são provenientes, principalmente, do quadrante leste. A velocidade média anual dos ventos é de $2,8 \mathrm{~m} / \mathrm{s}$, chegando a $10 \mathrm{~m} / \mathrm{s}$ na direção nordeste (ALMEIDA; BARBIRATO, 2004).

\section{Automação de rotinas e cálculo dos parâmetros morfológicos em SIG}

Nessa primeira etapa metodológica do trabalho, dados vetoriais urbanos da cidade de Maceió, fornecidos pela Secretaria de Planejamento do Estado de Alagoas (Seplande), foram tratados. Os únicos dados vetoriais existentes consistem em cadastros realizados em 2005, em formato dwg (CAD), com camadas de construções, quadras, ruas e lotes.

Por meio do SIG, o programa comercial ArcGIS ${ }^{\circledR}$, foi possível converter e tratar esses dados em shapefile (arquivo de forma), o que também permitiu identificar algumas imprecisões no banco de dados vetoriais obtido. Por exemplo, algumas áreas dos edifícios, quando da conversão em shapefile, apresentavam-se como incorretas (áreas negativas ou muito pequenas), alguns polígonos foram abertos e diferentes tipos de superfícies (edifícios, estradas, vegetação) foram sobrepostos. Para evitar essas falhas, foram empregados alguns testes automáticos, para filtrar as informações incoerentes, conservando somente aqueles que têm significado físico relevante.
Num segundo momento, foram criadas rotinas de cálculo com o auxílio das ferramentas e técnicas avançadas de geoprocessamento fornecidas pelo ArcToolbox do programa. Tais ferramentas foram empregadas na construção de um modelo, no ambiente do módulo Modelbuilder do ArcMAP®, o que permitiu automatizar o cálculo dos indicadores morfológicos para qualquer conjunto de dados vetoriais urbanos (em 2D e meio) ${ }^{1}$.

\section{Definição da malha}

A fim de realizar a caracterização de áreas homogêneas a partir do cálculo de parâmetros morfológicos, foi utilizada uma malha sobre os dados vetoriais urbanos. Foram avaliadas malhas cujas células de cálculo correspondiam a $500 \mathrm{~m} \mathrm{x}$ $500 \mathrm{~m}$ e $250 \mathrm{~m} \quad \mathrm{x} 250 \mathrm{~m}$. Como o dimensionamento de uma malha requer um recorte de objetos urbanos (ruas, edifícios), este recorte pode ser mais ou menos importante, dependendo das características do tecido urbano em questão, não devendo ser nem muito pequeno, para não representar apenas um fragmento pouco representativo do tecido urbano, nem demasiado grande, que possa englobar diferentes estruturas. Para a definição da resolução mais adequada da malha de estudo, foram realizados estudos estatísticos, visando analisar a predominância dos elementos no interior das duas resoluções consideradas inicialmente $(500 \mathrm{~m}$ e $250 \mathrm{~m})$. Os resultados obtidos, para os 50 bairros de Maceió, levaram à escolha da malha de 500 m, com 694 células de avaliação. $O$ desvio padrão e médias resultantes para alguns parâmetros selecionados para uma avaliação preliminar, tais como altura e densidade da área construída no solo, demonstraram melhor adequação da malha de maior resolução espacial (Tabela 1).

\section{Definição dos parâmetros morfológicos}

A metodologia utilizada para definição dos parâmetros da forma urbana a serem empregados foi a desenvolvida por Adolphe (2001). A proposta do autor partiu de uma modelagem espacial simplificada da morfologia urbana, resultando na definição de um conjunto de indicadores de desempenho ambiental de tecidos urbanos: densidade, rugosidade, porosidade, compacidade, contiguidade, rugosidade, prospecto médio, entre outros. As hipóteses climáticas e morfológicas consideradas, bem como os procedimentos metodológicos do desenvolvimento desse sistema

\footnotetext{
${ }^{1}$ Dados vetoriais urbanos em 2D e meio - ou pseudo-3D consistem em representação geométrica dos edifícios urbanos em 2D cuja altura (o "Z" dos vetores) seria apenas deduzida a partir das informações de atributo disponíveis.
} 
de indicadores podem ser encontrados, em detalhe, em Adolphe et al. (2002).

Os indicadores considerados neste trabalho podem ser lidos conforme as definições apresentadas nas Tabelas 2 e 3, a seguir. Para facilitar a leitura e compreensão desses indicadores, são apresentados valores de referência para três tecidos urbanos contrastados: subúrbio com casas individuais, centros históricos densos e centros verticalizados (SALAT, 2011; ADOLPHE et al., 2002).

Tabela 1 - Resultados estatísticos dos dados morfológicos para o tecido urbano de Maceió em duas resoluções de malha de cálculo

\begin{tabular}{|c|c|c|c|c|c|c|c|c|c|c|c|}
\hline \multirow{2}{*}{\multicolumn{2}{|c|}{$\begin{array}{c}\text { Estatísticas } \\
\text { Resolução espacial da malha }\end{array}$}} & \multicolumn{2}{|c|}{ Observações } & \multicolumn{2}{|c|}{ Mínimo } & \multicolumn{2}{|c|}{ Máximo } & \multicolumn{2}{|c|}{ Média } & \multicolumn{2}{|c|}{$\begin{array}{c}\text { Desvio } \\
\text { padrão }\end{array}$} \\
\hline & & 250 & 500 & 250 & 500 & 250 & 500 & 250 & 500 & 250 & 500 \\
\hline \multirow{4}{*}{ 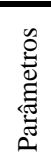 } & Altura média & 2163 & 694 & 3,00 & 3,00 & 35,0 & 23,7 & 5,80 & $\overline{5,81}$ & 2,77 & $\overline{2,51}$ \\
\hline & Coeficiente de aproveitamento & 2163 & 694 & 1,00 & 1,00 & 11,1 & 7,90 & 1,70 & 1,69 & $\mathbf{0 , 9 3}$ & $\mathbf{0 , 8 4}$ \\
\hline & Densidade construída & 2163 & 694 & 0,00 & 0,00 & 3,50 & 0,60 & 0,27 & 0,11 & 0,36 & $\mathbf{0 , 1 3}$ \\
\hline & Taxa de ocupação do solo & 2163 & 694 & 0,00 & 0,00 & 0,70 & 2,10 & 0,15 & 0,21 & $\mathbf{0 , 3 0}$ & 0,15 \\
\hline
\end{tabular}

Tabela 2 - Descrição dos principais indicadores relacionados à densidade utilizados no estudo

\begin{tabular}{|c|c|c|c|c|}
\hline \multirow[t]{2}{*}{ Indicador/parâmetro } & \multirow{2}{*}{ 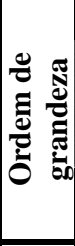 } & \multicolumn{3}{|c|}{ 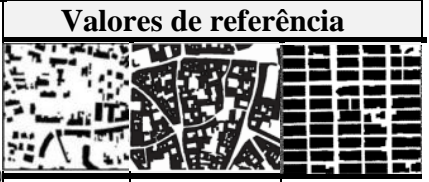 } \\
\hline & & Subúrbio & $\begin{array}{c}\text { Centro } \\
\text { histórico }\end{array}$ & $\begin{array}{l}\text { Centro } \\
\text { vertical }\end{array}$ \\
\hline $\begin{array}{l}\text { Altura média ponderada ou verticalidade } \\
\qquad H_{\text {med }}=\frac{\sum_{i}\left(h_{e d f_{i}} \times S_{s o l_{i}}\right)}{S_{s o l} \text { tot }} \\
\text { Onde } h_{e d f_{i}}=\text { altura do edifício } i ; S_{s o l_{i}}=\text { Área construída no solo do edifício ; } \\
S_{\text {sol }_{\text {tot }}=\text { Área total construída no solo da malha. }}\end{array}$ & - & 5,5 & 15,3 & 35,8 \\
\hline $\begin{array}{l}\text { Área útil total construída }\left(\mathrm{m}^{2}\right) \\
\text { A partir da altura foi deduzido o número de pavimentos (igual ao valor } \\
\text { arredondado da altura dividida por } 3 \text { ). Multiplica-se em seguida, o número de } \\
\text { pavimentos pela superfície no solo. } \\
\qquad S_{t o t}=\sum_{i}\left(\frac{h_{e d f_{i}}}{3} \cdot S_{\text {sol }_{i}}\right) \\
\text { Onde } h_{e d f_{i}}=\text { altura do edifício } i . ; S_{s o l_{i}}=\text { Área construída no solo do edifício } i .\end{array}$ & - & $2,0 \times 10^{5}$ & $2,0 \times 10^{6}$ & $4,0 \times 10^{6}$ \\
\hline $\begin{array}{l}\text { CA (Coeficiente de aproveitamento) } \\
\text { Definido como área útil total construída dividida pela área construída no solo. } \\
\qquad C A=\frac{S_{\text {tot }_{i}}}{S_{\text {sol }_{i}}} \\
\text { Onde } S_{\text {tot }} \text { é a Área útil total construída do edifício } i ; S_{\text {sol }_{i}}=\text { Área construída } \\
\text { no solo do edifício } i \text {. }\end{array}$ & $\begin{array}{c}1,0 \\
- \\
10,0 \\
(/)\end{array}$ & 1,0 & 5,0 & 12,0 \\
\hline $\begin{array}{l}\text { Densidade construída } \\
\text { Corresponde à soma das áreas úteis construídas, dividido pela área total da } \\
\text { malha. } \\
\qquad D s_{N} \text { const }=\frac{\sum_{i} S_{t o t_{i}}}{S} \\
\text { Onde } S_{t o t} \text { é a Área útil total construída do edifício } i ; \mathrm{S}=\text { Área total na malha; }\end{array}$ & $\begin{array}{c}0,5 \\
- \\
5,0 \\
(/)\end{array}$ & 0,5 & 3,0 & 5,0 \\
\hline $\begin{array}{l}\text { TO (Taxa de ocupação do solo) } \\
\text { Corresponde à soma das áreas construídas no solo, dividido pela área total da } \\
\text { malha. } \\
\qquad T O=\frac{\sum_{i} S_{S o l_{i}}}{S} \\
\text { Onde } S_{\text {Sol }_{i}}=\text { Área construída no solo do edifício } i ; \mathrm{S}=\text { Área total na malha; }\end{array}$ & $\begin{array}{c}0,1 \\
- \\
0,8 \\
(/)\end{array}$ & 0,15 & 0,65 & 0,53 \\
\hline
\end{tabular}


Tabela 3 - Descrição dos demais principais indicadores utilizados neste estudo

\begin{tabular}{|c|c|c|c|c|}
\hline \multirow{2}{*}{ Indicador/parâmetro Definição / cálculo } & \multirow{2}{*}{ ש. } & \multicolumn{3}{|c|}{ Valores de referência } \\
\hline & & Subúrbio & $\begin{array}{c}\text { Centro } \\
\text { histórico }\end{array}$ & $\begin{array}{c}\text { Centro } \\
\text { vertical }\end{array}$ \\
\hline $\begin{array}{l}\text { Rugosidade absoluta } \\
\text { Consiste na razão da soma das alturas ponderadas pela sua superfície pela } \\
\text { superfície total do tecido urbano considerado (construído e não construído). } \\
\qquad R_{g}=\frac{\sum_{c o n s t} S_{i} * H_{i}}{\sum_{c o n s t} S_{i}+\sum_{v a z i o} S_{j}} \\
\text { Onde } S_{i} \text { é area construída do edifício } i \text {, H é a sua altura, e } S_{j} \text { é a área no } \\
\text { elemento não construído } j \text {. }\end{array}$ & $\begin{array}{c}0,0 \\
- \\
35,0 \\
(\mathrm{~m})\end{array}$ & 0,8 & 7,1 & 14,3 \\
\hline $\begin{array}{l}\text { Prospecto médio } \\
\text { Relação da altura média ponderada pela largura da rua. } \\
\qquad P_{M}=H_{m e d} / l \\
\text { Onde } H_{m e d}=\text { Altura média ponderada dos edifícios na malha; } l=\text { Largura } \\
\text { da rua. }\end{array}$ & $\begin{array}{c}0,1 \\
- \\
3,0 \\
(/)\end{array}$ & 0,55 & 3,9 & 3,2 \\
\hline
\end{tabular}

Esse sistema de indicadores de morfologia urbana foi incorporado na plataforma GIS, ArcMAP/ArcGIS, e aplicado à análise do tecido urbano de Maceió.

\section{Análise de componentes principais e análise de agrupamento}

Inicialmente, uma ampla gama de parâmetros foi lançada na rotina de cálculo, a fim de completar uma Análise de Componentes Principais (ACP).

Uma ACP consiste em análise estatística que pode ser usada para avaliar as inter-relações entre um 
grande número de variáveis, de modo a condensar a informação contida nelas em um conjunto menor de variáveis estatísticas, com perda mínima de informação. A utilização dessa técnica de análise multivariada visa minimizar as redundâncias que possam existir, possibilitando a captação da maior variabilidade dos dados em poucas componentes, tornando mais simples o mapeamento das informações (ALENCAR, 2009).

Num segundo momento, lançou-se mão de uma análise de agrupamentos, ou clustering analysis. Este método estatístico não paramétrico visa identificar e agrupar objetos por similaridade, conforme algum atributo particular, possibilitando a identificação de padrões de comportamento. $\mathrm{O}$ método de $k$-means clustering foi a técnica mais adequada para a aplicação na metodologia deste estudo. $\mathrm{O}$ algoritmo desse método consiste em escolher uma partição inicial dos dados e, em seguida, modificar os membros de classes, a fim de obter uma nova partição que revele melhor a estrutura natural dos dados iniciais. Assim, os pontos de $k$ são especificados como centroides (médias de cada atributo) de classes $k$, calculandose a distância euclidiana entre cada elemento e os centros destes. Os elementos são, então, atribuídos à classe cujo centro é o mais próximo. Os centros de cada classe são, em seguida, recalculados, e o procedimento é repetido, até que o algoritmo possa convergir para uma posição estável, minimizando a variância a cada iteração (DIDAY et al., 1982). Uma boa divisão de um conjunto de observações em grupos é aquela em que os elementos de um mesmo grupo são os mais parecidos entre si (menor variância intraclasse) e em que os elementos de grupos diferentes são os mais diferentes entre si (variância interclasse). Esse passo é dado para verificar a robustez dos grupos de objetos gerados.

Ressalta-se que as classes tipológicas destacadas neste trabalho são puramente morfológicas e independentes de seus usos.

\section{Estudo do impacto da morfologia urbana no consumo de energia dos edifícios}

Para a simulação dinâmica do desempenho energético dos edifícios, utilizou-se o código CitySim, desenvolvido pelo Laboratório LESO-PB da Escola Politécnica Federal de Lausanne-Suíça. CitySim propõe acoplamento de modelos para simulação dinâmica e otimização do fluxo energético na relação do edifício com seu entorno (ROBINSON, 2011).

O código consta de um modelo térmico simplificado que consiste em versão refinada do modelo de analogia ao circuito elétrico nodal de
Nielsen (2005), mais especificamente baseado na rede resistor-capacitor (ROBINSON, 2011). Em síntese, o fluxo de calor entre a parede e o ar exterior pode ser representado por uma corrente elétrica através de um resistor que liga os dois nós correspondentes, e a inércia da parede pode ser representada pela capacitância ligada a esse nó. A temperatura do ar externo e a temperatura superficial são influenciadas pela direção e velocidade do vento, bem como pelas trocas de radiação de ondas curtas e longas. O modelo térmico foi validado parcialmente por comparação ao código ESP-r (CLARK, 2001; KAMPF, 2009), para um conjunto de cenários (monozona e multizona).

Para previsão da radiação solar em contexto urbano, emprega-se o algoritmo simplificado de radiosidade (Simplified Radiosity Algorithm) de Robinson e Stone (2004). A partir de um esquema de discretização, a abóbada celeste é dividida em 145 partes (TREGENZA; SHARPLES, 1993), cada uma compreendendo um ângulo e uma radiância, calculada pelo modelo de Perez (PEREZ; SEALS; MICHALSKY, 1993). Para isso, consideram-se frações de visibilidade solar e do céu a partir de cada superfície, a declividade do plano receptor, o efeito da redução da radiação direta em função das obstruções do entorno e o efeito da radiação difusa. A mesma rotina de cálculo é também utilizada para calcular a irradiância de onda longa (refletida pelos elementos da cena urbana), dadas as superfícies e temperaturas do ar correspondentes, bem como para modelar o ambiente luminoso externo e interno. $\mathrm{O}$ modelo obteve bons resultados quando comparado ao modelo RADIANCE (WARD LARSEN; SHAKESPEARE, 1997) para parâmetros de entrada equivalentes (ROBINSON; STONE, 2004).

Os modelos matemáticos completos a partir dos quais foi programado o CitySim podem ser encontrados em Robinson (2011). Para avaliar sua precisão preditiva, o programa ainda não contou com validação por meio de estudos empíricos; apenas por método de comparação intermodelos (KAMPF, 2009).

As variáveis de entrada do CitySim podem ser inseridas para parâmetros de clima, geometria e especificações termofísicas. Para o clima, faz-se necessário definir uma localidade geográfica e gerar um ano climático completo em intervalo horário. Para a geometria, considera-se um conjunto de edifícios em 3D, para os quais é possível inscrever a complexidade da forma construída, inserindo-se diferentes alturas, distâncias e orientações dos edifícios. O modelo permite também a definição de um perfil de 
obstruções em função da topografia do sítio urbano. As aberturas dos edifícios, na escala considerada, são cadastradas por meio da atribuição de uma fração de abertura por fachada. Quanto às especificações termofísicas, o modelo permite atribuir valores, entre outros, para transmitância térmica dos fechamentos e aberturas, fator solar, refletância solar de onda curta, entre outros. Pode ser definida ainda uma taxa de infiltração por volume construído e as características de um sistema mecânico simplificado de condicionamento de ar.

Para o estudo de caso neste trabalho, o modelo foi aplicado para avaliar grupos de edifícios existentes da cidade de Maceió. Utilizaram-se os dados vetoriais urbanos, obtidos na Seplande. As construções existentes tiveram suas características completadas por meio de especificações físicas dos materiais, obtidas por observações e registros em trabalho de campo. Para cada classe tipológica destacada, foram adotadas especificações termofísicas. Algumas das variáveis principais podem ser encontradas na Tabela 4.

O cálculo realizado para o balanço energético dos edifícios baseia-se na demanda para condicionamento térmico do ar e iluminação artificial dos espaços internos das edificações.

\section{Resultados e discussões}

Os resultados são apresentados a seguir em duas etapas. Primeiro, discute-se a análise estatística dos dados morfológicos obtidos, apresentando-se, ao fim, uma cartografia da distribuição das classes tipológicas elaborada para a cidade de Maceió. Na descrição de cada classe de referência, é considerada, principalmente, a caracterização da forma pelo conjunto de atributos morfológicos obtidos. Na sequência, apresenta-se o desempenho energético para elas.

\section{Análise de dados por ACP e análise de agrupamento}

Os dados para todos os indicadores calculados no ArcMAP/GIS ${ }^{\circledR}$ foram analisados com auxílio do aplicativo XLStat, no Excel.

Inicialmente, foi analisada a matriz de correlação entre os indicadores calculados para as 694 zonas da malha (Tabela 5). Percebe-se que as correlações são, muitas vezes, bastante fortes entre certas variáveis, como destacado na cor laranja, na matriz abaixo. A fim de evitar redundância nas informações, decidiu-se conservar apenas um dos parâmetros dos pares em que a correlação é importante.

Esses elevados valores de correlação resultam do fato de que certas variáveis possuem uma forte dependência entre elas. Valores intermediários indicam uma correlação moderada entre as variáveis, como a altura média ponderada e o volume construído $(\mathrm{r}=0,51)$. Outras variáveis possuem forte correlação negativa, como a área construída e a porosidade $(\mathrm{r}=-0,85)$, ou seja, quanto maior for a área construída, menor será a porosidade do tecido urbano.

Tabela 4 - Resumo dos parâmetros principais do modelo de cálculo energético para o estudo de caso

\begin{tabular}{|c|c|c|c|c|c|c|c|c|}
\hline Parâmetros & $\begin{array}{c}\text { Formatos } \\
\text { entrada }\end{array}$ & Pricnipais variáveis & Unid & $\begin{array}{c}\text { Classe } \\
1\end{array}$ & $\begin{array}{c}\text { Classe } \\
2\end{array}$ & $\begin{array}{c}\text { Classe } \\
3\end{array}$ & $\begin{array}{c}\text { Classe } \\
4\end{array}$ & $\begin{array}{c}\text { Classe } \\
5\end{array}$ \\
\hline \multirow{6}{*}{ Tecnologia } & \multirow{7}{*}{$\begin{array}{l}\text { Arquivo } \\
\text { de } \\
\text { entrada } \\
(. x m l)\end{array}$} & Transmitância térmica & $\mathrm{W} / \mathrm{m}^{2} \mathrm{~K}$ & 0,00 & 0,00 & 1,80 & 2,00 & 2,00 \\
\hline & & Fator solar elementos opacos & & 2,40 & 2,40 & 1,40 & 2,40 & 2,20 \\
\hline & & Fator solar médio dos vidros & & 0,60 & 0,60 & 0,60 & 0,60 & 0,60 \\
\hline & & Abertura nas fachadas & $\%$ & 0,50 & 0,50 & 0,20 & 0,50 & 0,20 \\
\hline & & Refletividade em ondas curtas & $\mu \mathrm{m}$ & 0,20 & 0,20 & 0,20 & 0,20 & 0,20 \\
\hline & & K Ground & & 0,15 & 0,15 & 0,15 & 0,15 & 0,15 \\
\hline Geometria & & $\begin{array}{l}\text { Paredes }(\mathrm{X} ; \mathrm{Y} ; \mathrm{Z}) \\
\text { Coberta }(\mathrm{X} ; \mathrm{Y} ; \mathrm{Z}) \\
\text { Solo }(\mathrm{X} ; \mathrm{Y} ; \mathrm{Z}) \\
\text { Orientação }\end{array}$ & \multicolumn{6}{|c|}{ Dados vetoriais urbanos Maceió - AL. } \\
\hline Clima & $\begin{array}{l}\text { Arquivo } \\
\text { climático } \\
\text { (.cli) }\end{array}$ & $\begin{array}{l}\text { Irradiância horizontal difusa } \\
\text { Irradiância solar natural } \\
\text { Velocidade do vento } \\
\text { Direção do vento } \\
\text { Umidade relativa } \\
\text { Precipitação } \\
\text { Nebulosidade } \\
\text { Temperatura do ar }\end{array}$ & \multicolumn{6}{|c|}{$\begin{array}{c}\text { Dados meteorológicos } \\
\text { Maceió - AL: } 9^{\circ} 40^{\prime} S ; 38^{\circ} 37^{\prime} \mathrm{O}\end{array}$} \\
\hline
\end{tabular}




\begin{tabular}{|c|c|c|c|c|c|c|c|c|c|c|c|c|c|c|}
\hline Variáveis & 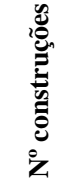 & 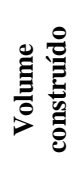 & 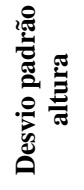 & 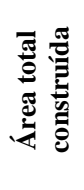 & $\stackrel{O}{\mathscr{H}}$ & 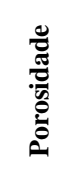 & 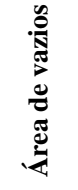 & 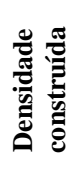 & 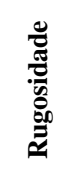 & త্ & 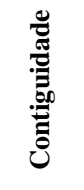 & 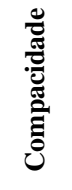 & 焉 & 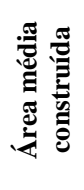 \\
\hline $\begin{array}{l}\mathbf{N}^{\mathbf{o}} \\
\text { construções }\end{array}$ & 1,00 & & & & & & & & & & & & & \\
\hline $\begin{array}{l}\text { Volume } \\
\text { construído }\end{array}$ & 0,68 & 1,00 & & & & & & & & & & & & \\
\hline $\begin{array}{l}\text { Desvio padrão } \\
\text { altura }\end{array}$ & 0,04 & 0,52 & 1,00 & & & & & & & & & & & \\
\hline $\begin{array}{l}\text { Área total } \\
\text { construída }\end{array}$ & 0,63 & 0,98 & 0,55 & 1,00 & & & & & & & & & & \\
\hline TO & 0,91 & 0,98 & 0,22 & 0,85 & 1,00 & & & & & & & & & \\
\hline Porosidade & $-0,91$ & $-0,89$ & $-0,22$ & $-0,85$ & $-1,00$ & 1,00 & & & & & & & & \\
\hline Área de vazios & $-0,91$ & $-0,89$ & $-0,22$ & $-0,85$ & $-1,00$ & 1,00 & 1,00 & & & & & & & \\
\hline $\begin{array}{l}\text { Densidade } \\
\text { construída }\end{array}$ & 0,63 & 0,98 & 0,55 & 0,98 & 0,85 & $-0,85$ & $-0,85$ & 1,00 & & & & & & \\
\hline Rugosidade & 0,68 & 0,98 & 0,52 & 0,98 & 0,89 & $-0,89$ & $-0,89$ & 0,98 & 1,00 & & & & & \\
\hline CA & $-0,03$ & 0,51 & 0,90 & 0,55 & 0,18 & $-0,18$ & $-0,18$ & 0,55 & 0,51 & 1,00 & & & & \\
\hline Contiguidade & 0,11 & 0,11 & 0,01 & 0,10 & 0,13 & $-0,13$ & $-0,13$ & 0,10 & 0,11 & 0,01 & 1,00 & & & \\
\hline Compacidade & $-0,09$ & $-0,06$ & 0,03 & $-0,06$ & $-0,09$ & 0,09 & 0,09 & $-0,06$ & $-0,06$ & 0,04 & $-0,99$ & 1,00 & & \\
\hline $\begin{array}{l}\text { Altura } \\
\text { ponderada }\end{array}$ & $-0,03$ & 0,51 & 0,90 & 0,54 & 0,18 & $-0,18$ & $-0,18$ & 0,54 & 0,51 & 0,99 & 0,01 & 0,04 & 1,00 & \\
\hline $\begin{array}{l}\text { Área média } \\
\text { construída }\end{array}$ & $-0,11$ & 0,18 & 0,40 & 0,20 & 0,02 & $-0,02$ & $-0,02$ & 0,20 & 0,18 & 0,50 & 0,03 & 0,04 & 0,51 & 1,00 \\
\hline
\end{tabular}

\section{Primeira ACP}

Os quatorze indicadores iniciais foram analisados entre eles, demonstrando, conforme os gráficos abaixo, o número de indicadores a serem considerados, o que corresponde ao primeiro ponto de viragem encontrado na curva (CATTELL, 1966) e o percentual da variabilidade acumulada, representada pelos eixos dos fatores, respectivamente (Figura 2). Esse percentual, para ser válido nessa abordagem, deve ser elevado para a relação entre os dois primeiros fatores. E, como se pode observar nessa primeira ACP, devido ao grande número de informações sobrepostas, esse percentual é relativamente baixo.

Os gráficos da Figura 2 permitem observar que algumas das variáveis estudadas são bastante próximas, em particular coeficiente de aproveitamento, altura média, densidade construída, área total construída, por exemplo. Visto isso, é possível simplificar a ACP, mantendo, a cada vez, apenas um parâmetro, sem perda significativa de informação.

\section{Segunda ACP e análise de agrupamento}

Os parâmetros considerados na segunda ACP foram porosidade, rugosidade, altura média, densidade construída, compacidade e contiguidade (Figura 3).

Os gráficos da Figura 3 permitem constatar que os parâmetros não se apresentam mais tão próximos, permitindo observações mais relevantes. Além disso, alguns dos parâmetros variam perpendicularmente e outros inversamente, o que podem garantir a relevância dessas observações na aplicação em questão. Relacionando por pares, isso seria o caso da relação entre a contiguidade e a compacidade e entre a densidade construída e a Porosidade.

Esta análise serviu a dois objetivos principais. De um lado, permitiu compreender a relação dos parâmetros morfológicos entre si e, de outro, possibilitou extrair de uma grande massa de informações os dados mais relevantes (e não redundantes) para a realização da análise e a classificação tipo-morfológica do tecido urbano. 
Para a análise de agrupamento dos mesmos dados, foram realizadas cinco iterações com dez repetições, convergindo a uma variância intraclasse de 20,55 e uma variância interclasse de 2,13 (determinante=0,006). Na Tabela 6, a seguir, pode ser encontrada uma síntese dessas informações por classe.

O método permitiu destacar, portanto, cinco classes principais, que podem ser facilmente identificadas por termos descritivos correntes da morfologia urbana (ver Tabela 7). Essas classes serão mais bem descritas e analisadas na sequência do trabalho.

\section{Cartografia da forma urbana de Maceió e as cinco classes de referência}

Apresentam-se, a seguir, seis mapas temáticos, que representam a compacidade, a contiguidade, a densidade construída, a porosidade, a verticalidade e a rugosidade da malha, as quais caracterizam a forma urbana construída em Maceió (Figuras 4 a 9).

Figura 2 - Representações gráficas da primeira ACP
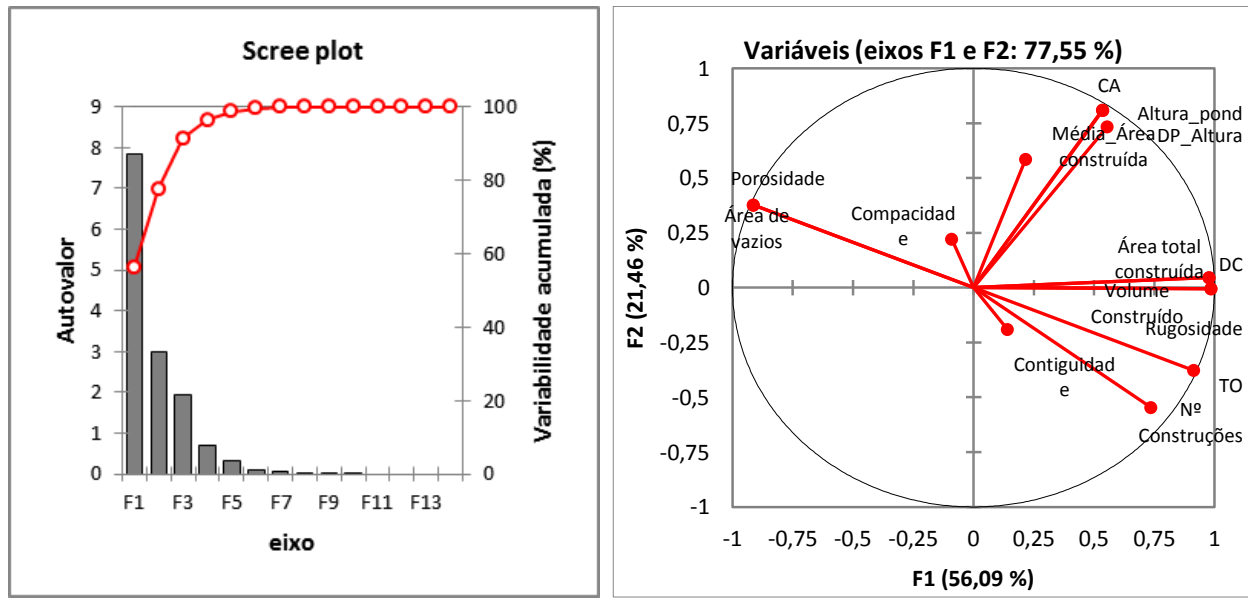

Figura 3 - Representações gráficas da segunda ACP
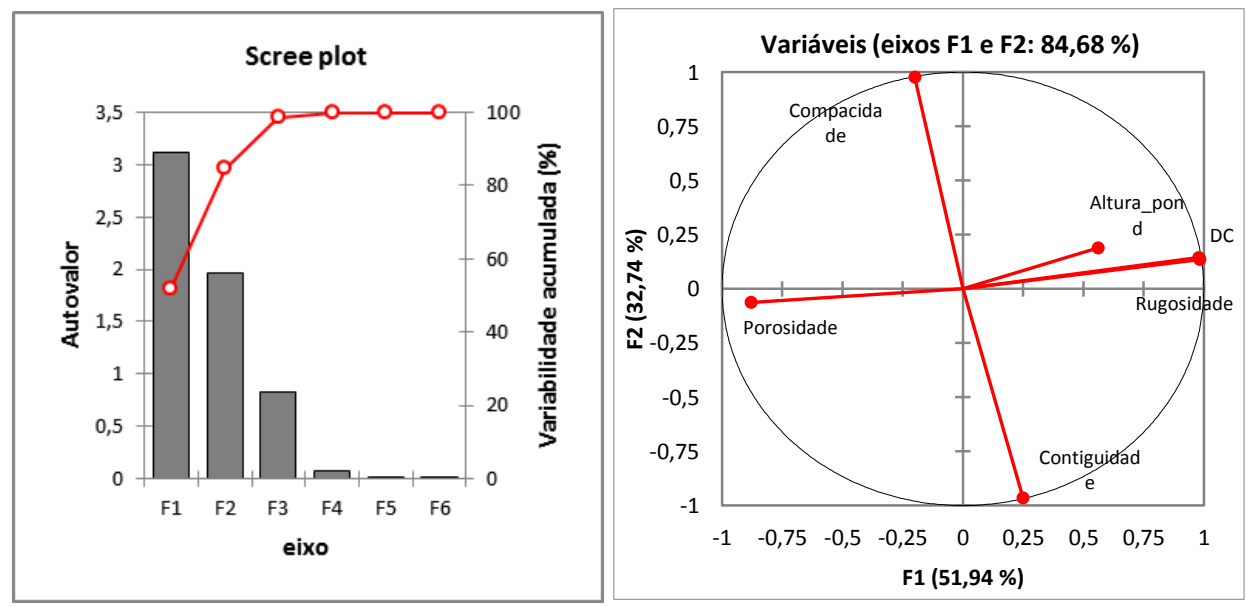

Tabela 6 - Resumo das iterações realizadas na análise de agrupamento

\begin{tabular}{l|c|c|c|c|c}
\hline \multicolumn{1}{c|}{ Classe } & $\mathbf{1}$ & $\mathbf{2}$ & $\mathbf{3}$ & $\mathbf{4}$ & $\mathbf{5}$ \\
\hline Número de objetos & 260 & 59 & 223 & 17 & 135 \\
Variância interclasse & 0,71 & 1,02 & 4,11 & 16,26 & 4,23 \\
Distância mínima ao centroide & 0,09 & 0,16 & 0,32 & 0,68 & 0,34 \\
Distância média ao centroide & 0,77 & 0,89 & 1,31 & 3,55 & 1,82 \\
Distância máxima ao centroide & 1,65 & 2,74 & 17,61 & 7,86 & 4,34 \\
\hline
\end{tabular}

222 Martins, T. A. de L.; Bonhomme, M.; Adolphe, L. 
Tabela 7 - Cinco classes tipológicas urbanas segundo indicadores morfológicos.

\begin{tabular}{|c|c|c|c|c|c|c|c|}
\hline Classe & 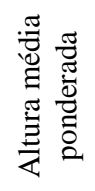 & $\begin{array}{l}\frac{0}{0} \\
\frac{\tilde{J}}{0} \\
\tilde{O} \\
\tilde{O} \\
0\end{array}$ & 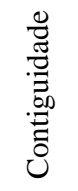 & 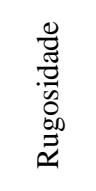 & 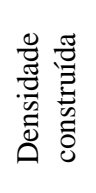 & 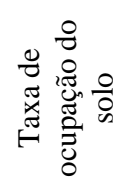 & $\begin{array}{l}\frac{\pi}{0} \\
\frac{\pi}{0} \\
0 \\
0 \\
0\end{array}$ \\
\hline 1 Horizontal disperso & 4,22 & 4,75 & 0,07 & 0,104 & 0,08 & 0,08 & 0,97 \\
\hline 2 Vertical baixo & 9,11 & 5,18 & 0,02 & 0,252 & 0,88 & 0,22 & 0,96 \\
\hline 3 Horizontal contínuo/geminado & 6,29 & 3,87 & 0,38 & 2,735 & 2,38 & 0,74 & 0,67 \\
\hline 4 Coletivo vertical & 17,04 & 4,94 & 0,22 & 1,578 & 4,15 & 0,49 & 0,90 \\
\hline 5 Horizontal compacto & 5,15 & 3,66 & 0,03 & 1,714 & 0,75 & 0,56 & 0,70 \\
\hline
\end{tabular}

Figura 4 - Mapa da compacidade do tecido urbano de Maceió, AL

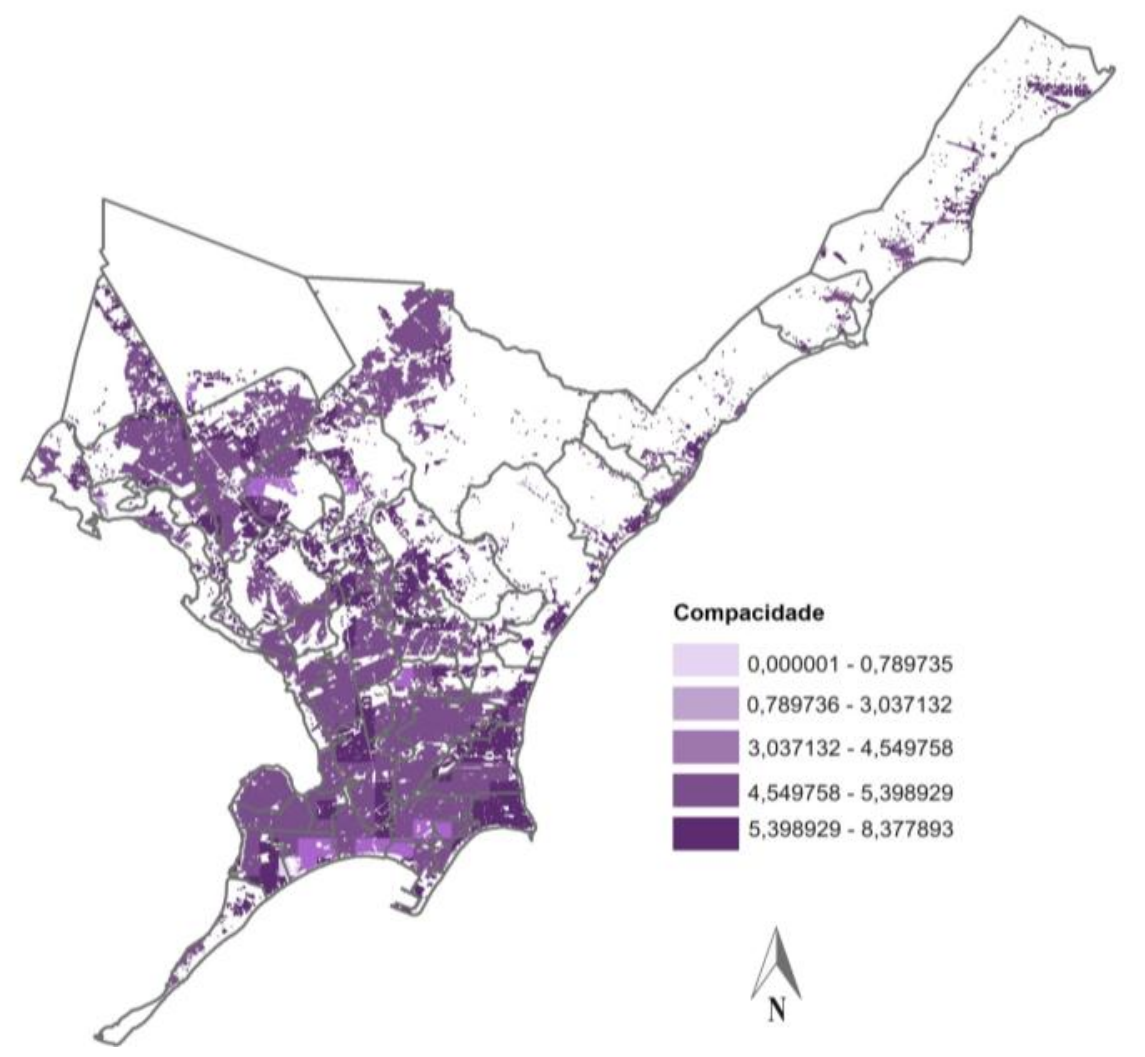

O primeiro mapa apresentado (Figura 4) caracteriza a compacidade das construções urbanas de Maceió. Esse atributo descreve a superfície da envoltória exposta ao exterior em relação a seu volume construído (Tabela 3). Quanto maior a compacidade, maior a superfície exposta ao exterior, maior o aporte solar das fachadas. A compacidade, assim como o fator de forma, é um dos indicadores de forma mais pertinentes no estudo do desempenho energético dos edifícios, influenciando no cálculo teórico da demanda de energia (SALAT, 2011; APUR, 2007; ADENE, 2008; CARLO; LAMBERTS, 2010). O interesse desse coeficiente em relação ao tradicional fator de forma $\left(A_{\text {ext }} / V\right)$ consiste em não atribuir um peso hegemônico aos grandes edifícios em detrimento dos menores, o que obrigaria, no cálculo do fator de forma médio para dado tecido urbano, ter de ponderar seu valor pela superfície total construída. Observa-se que, globalmente, o tecido urbano de Maceió apresenta uma compacidade relativamente expressiva, com regiões onde esta se apresenta ainda mais elevada $(5,38-8,37)$, a exemplo dos bairros situados nas centralidades da planície litorânea; e compacidades mais reduzidas $(0,70$ 5,03 ) nos bairros mais adensados, como o centro da cidade e os bairros situados na orla lagunar, com a presença de edificações geminadas, acompanhando de forma complementar os valores da contiguidade (Figura 5). As diferenças bastante 
significativas identificadas entre bairros de maior e menor compacidade $(0,7-8,37)$ podem representar diferenças importantes na demanda de energia entre eles. Minimizar fachadas expostas à insolação (reduzindo sua compacidade) pode também implicar a redução do potencial de aproveitamento da luz e da ventilação natural. Por isso, a fim de melhor caracterizar o desempenho ambiental da forma construída, faz-se necessário observar um conjunto de indicadores pertinentes (compacidade, rugosidade, densidade, verticalidade, etc.).

A Figura 6 mostra as regiões mais e menos adensadas da cidade. Em virtude do forte processo de verticalização das zonas da orla marítima da cidade, estas se apresentam como as áreas mais densamente construídas, verticalizadas e rugosas (Figuras 6, 8 e 9).
O quarto mapa (Figura 7) hierarquiza valores referentes à porosidade da malha urbana, destacando algumas áreas da orla marítima da cidade no sentido do litoral norte. Isso é resultado, de um lado, dos espaços livres existentes e afastamentos dos edifícios verticais (gerados pelas exigências de recuos progressivos impostos pelo código de edificações) e, de outro, da existência de edificações individuais dispersas em alguns bairros residenciais situados na periferia da cidade. Quanto à rugosidade (Figura 9), os valores mais importantes encontram-se nas áreas mais adensadas e compactas, nos conjuntos modernos da orla marítima ou no centro da cidade. As menos expressivas podem ser identificadas nos tecidos horizontais da periferia da cidade. A porosidade e a rugosidade caracterizam o efeito global do tecido urbano no incremento ou na redução da velocidade média do vento respectivamente.

Figura 5 - Mapa da contiguidade do tecido urbano de Maceió, AL

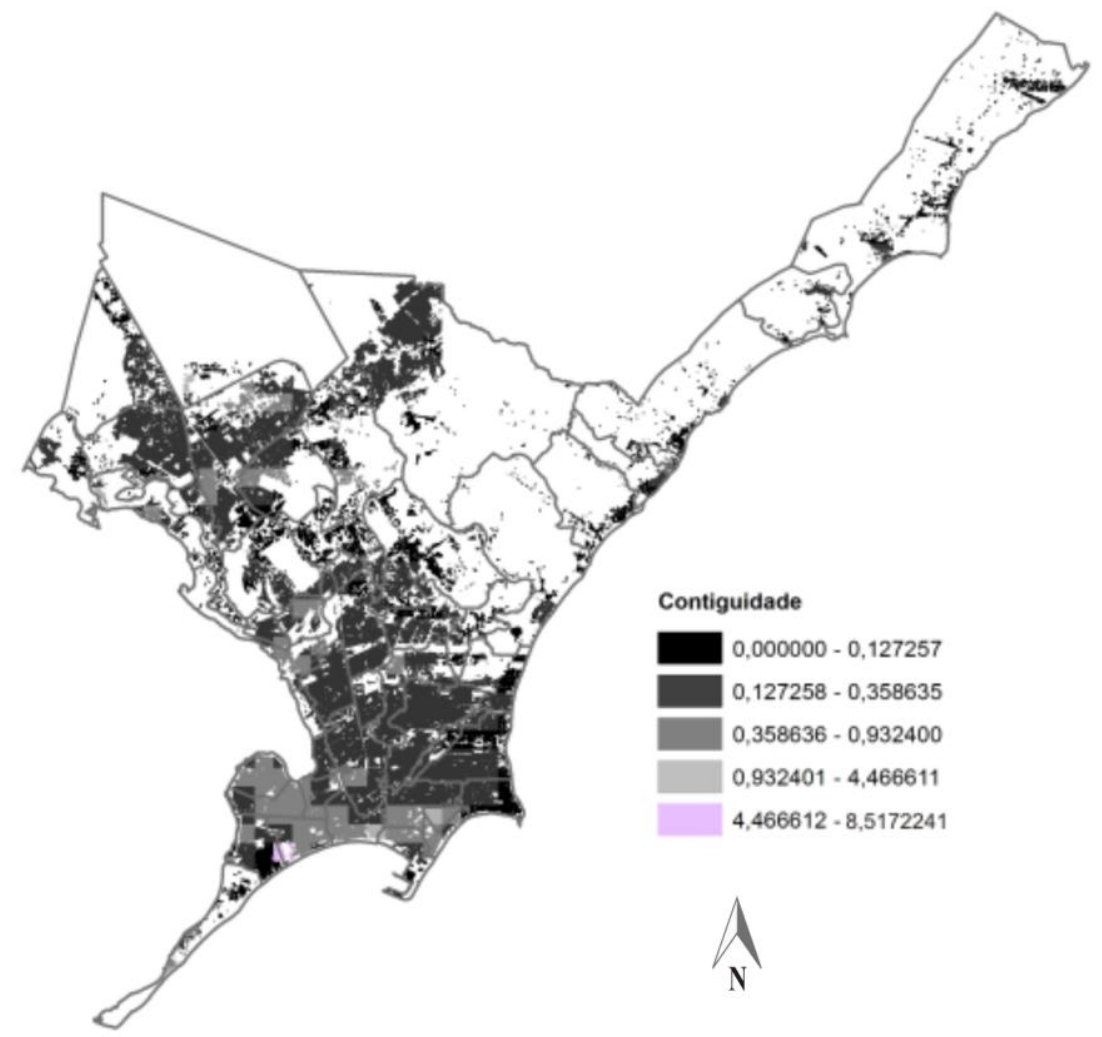

224 Martins, T. A. de L.; Bonhomme, M.; Adolphe, L. 
Figura 6 - Mapa da densidade construída do tecido urbano de Maceió, AL

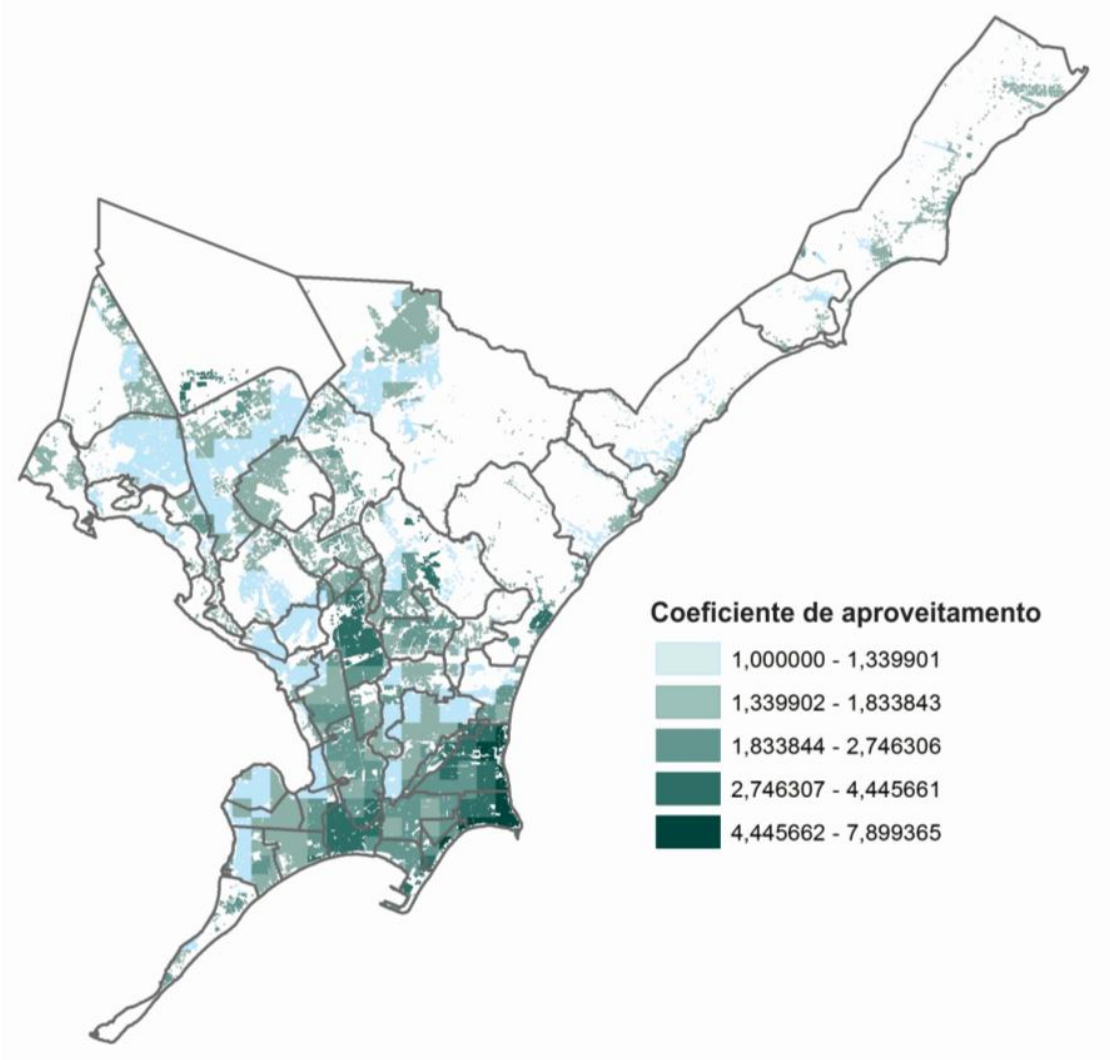

Figura 7 - Mapa da porosidade do tecido urbano de Maceió, AL

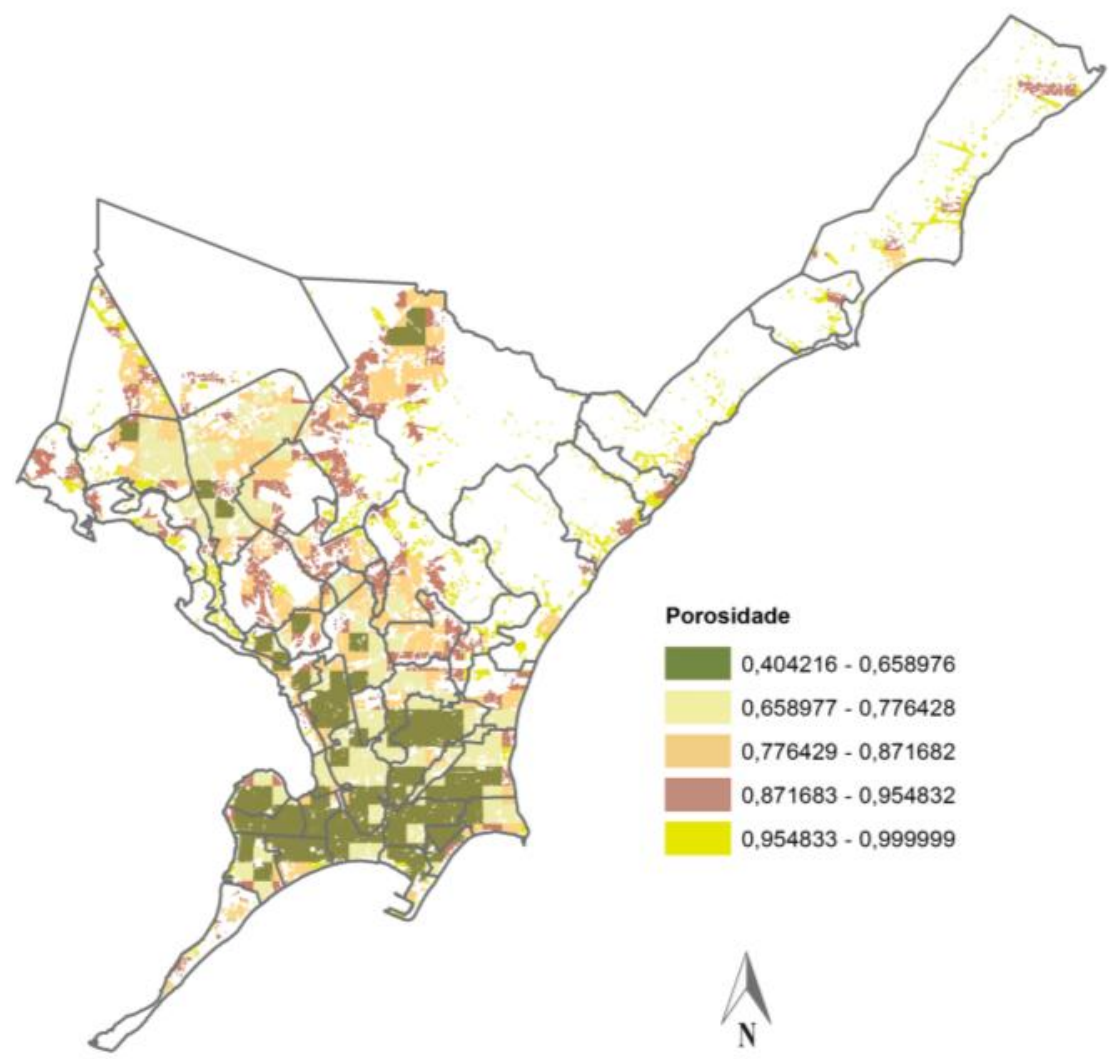

Análise do impacto da morfologia urbana na demanda estimada de energia das edificações: um estudo de caso na 
Figura 8 - Mapa da verticalidade do tecido urbano de Maceió, AL

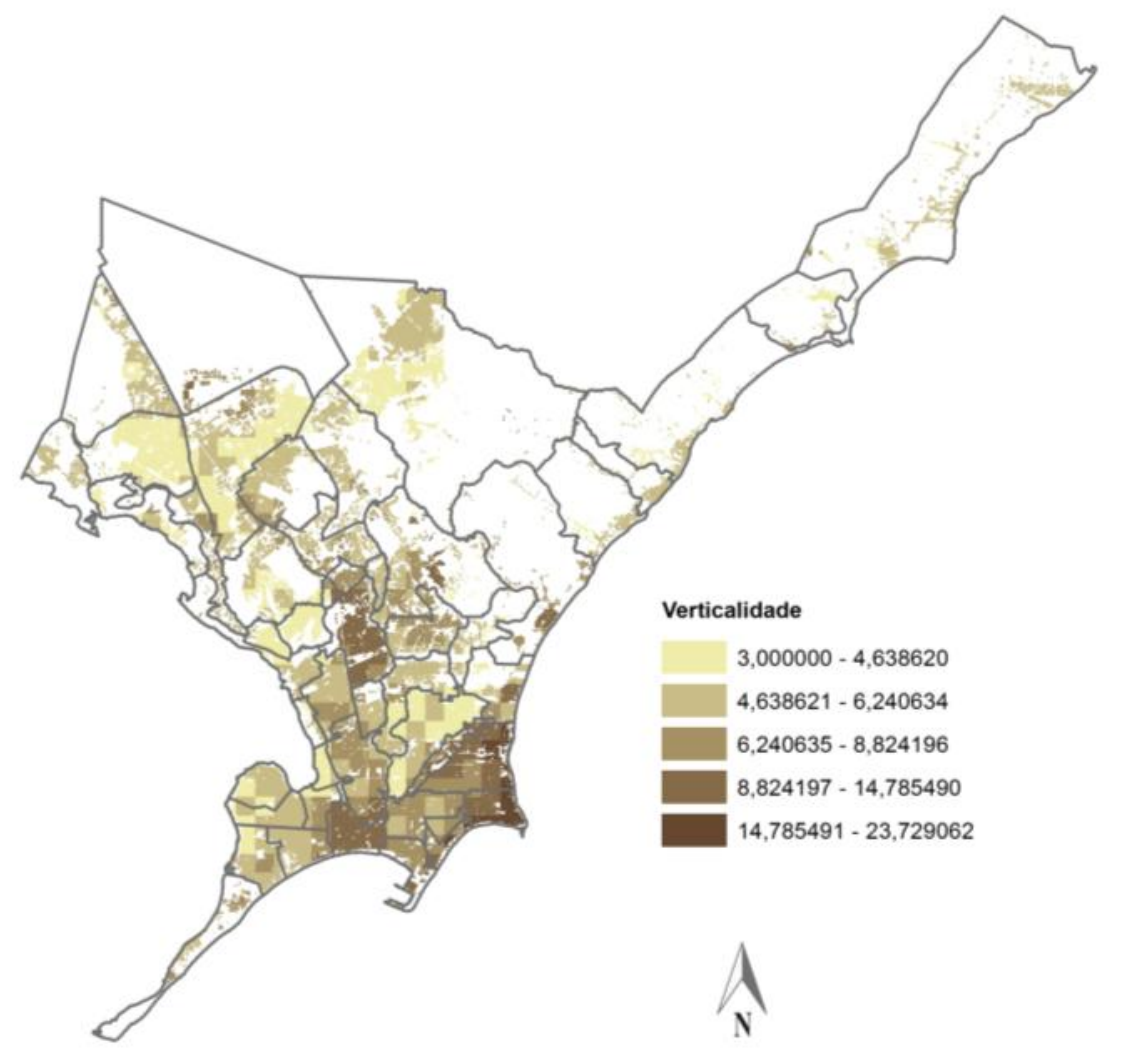

Figura 9 - Mapa da rugosidade do tecido urbano de Maceió, AL

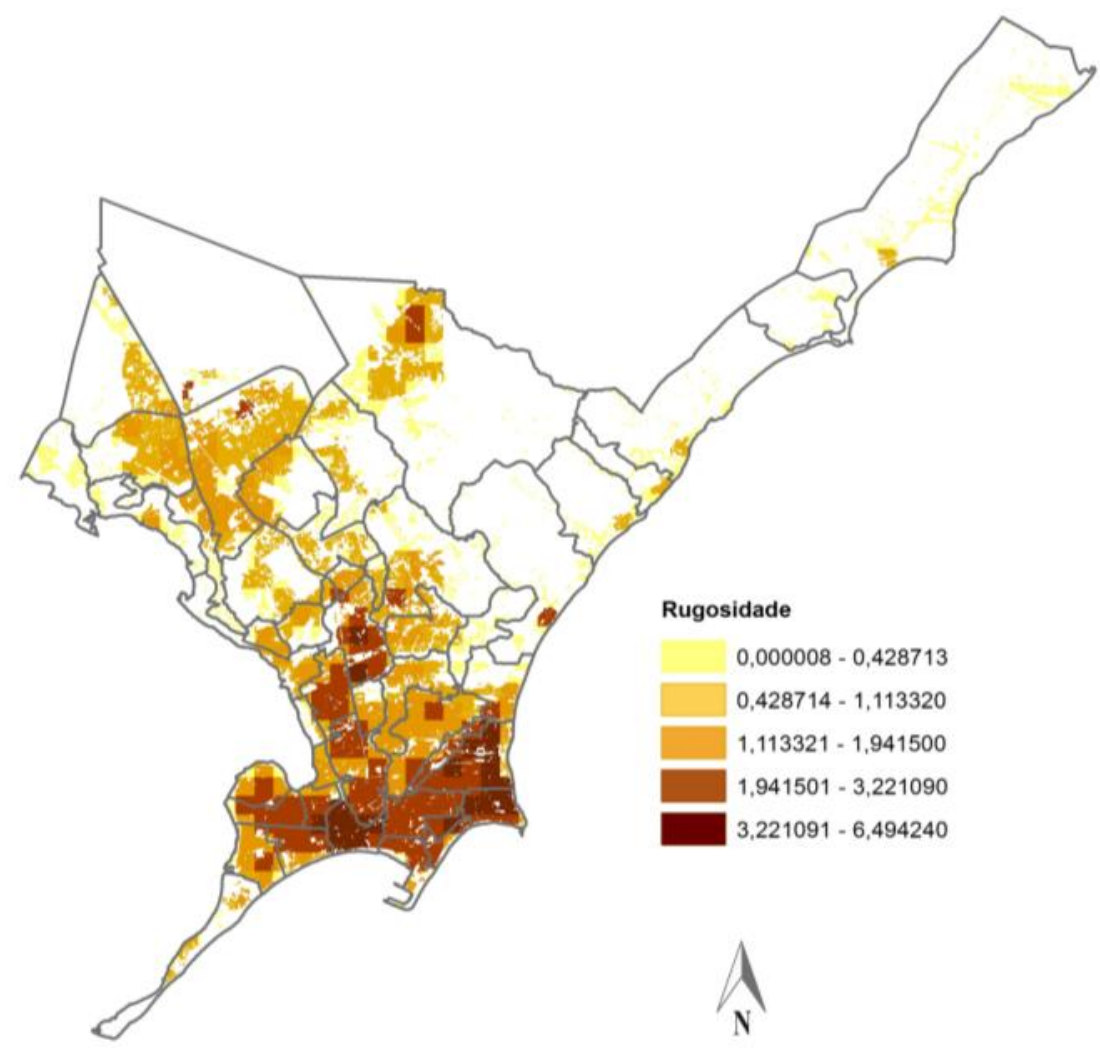

226 Martins, T. A. de L.; Bonhomme, M.; Adolphe, L. 
O mapa a seguir representa a cartografia final das classes tipológicas da forma urbana de Maceió, obtidas a partir da análise do conjunto dos indicadores supracitados (Figura 10).

\section{Classe 1: horizontal disperso}

A classe 1 compreende, principalmente, os bairros da periferia da cidade, tecido caracterizado predominantemente por ser horizontal com edificações residenciais individuais e isoladas (Figura 11). Essa classe representa $37 \%$ do tecido urbano de Maceió e apresenta uma densidade construída pouco importante, de 0,08. Com edificações mais baixas $(4,22 \mathrm{~m}$ de altura, em média), a forma possui uma compacidade mais elevada $(4,74)$.

\section{Figura 10 - Cartografia das classes tipológicas mais representativas da forma urbana de Maceió}

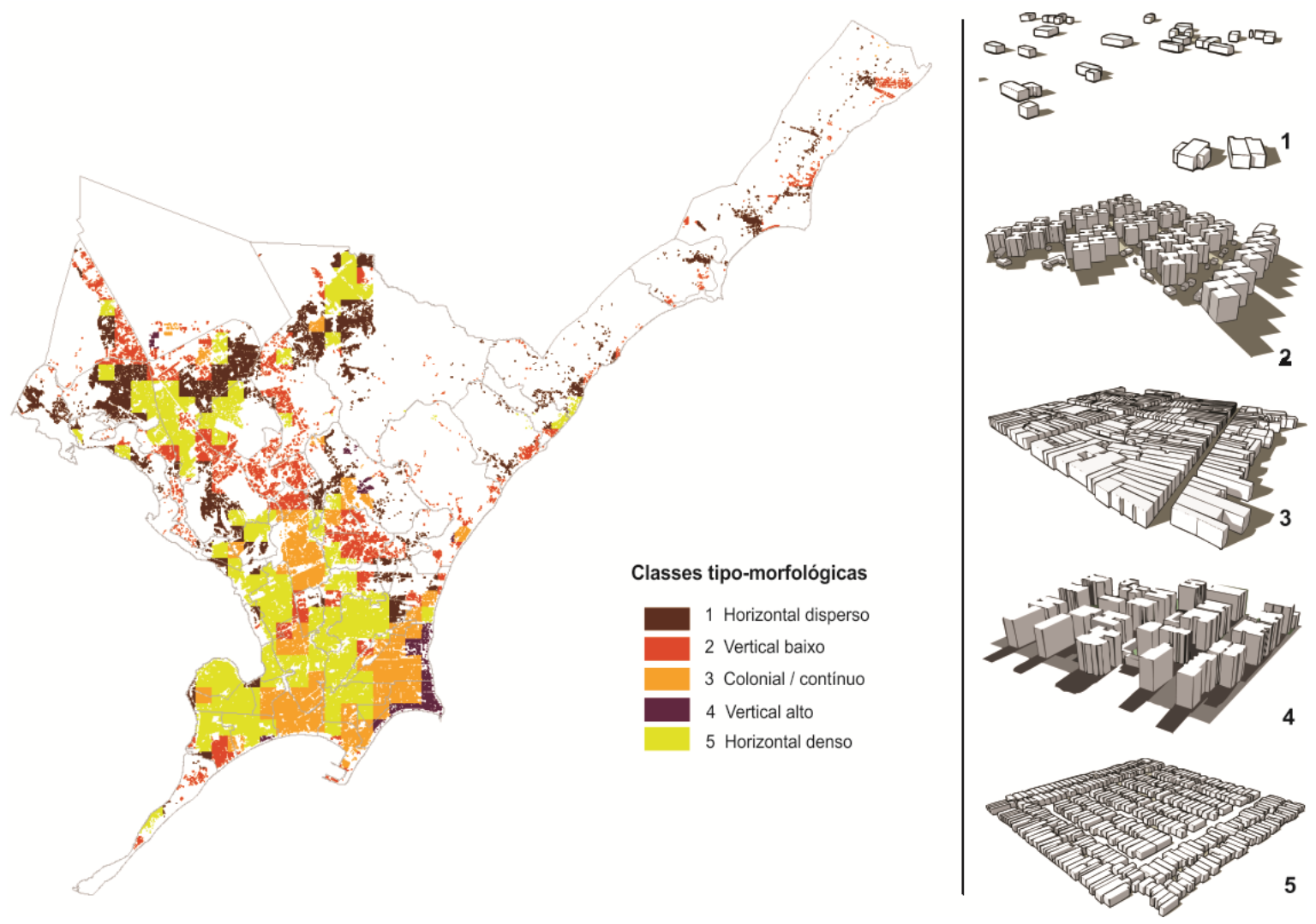

Figura 11 - Representações de bairro situado predominantemente na classe 1
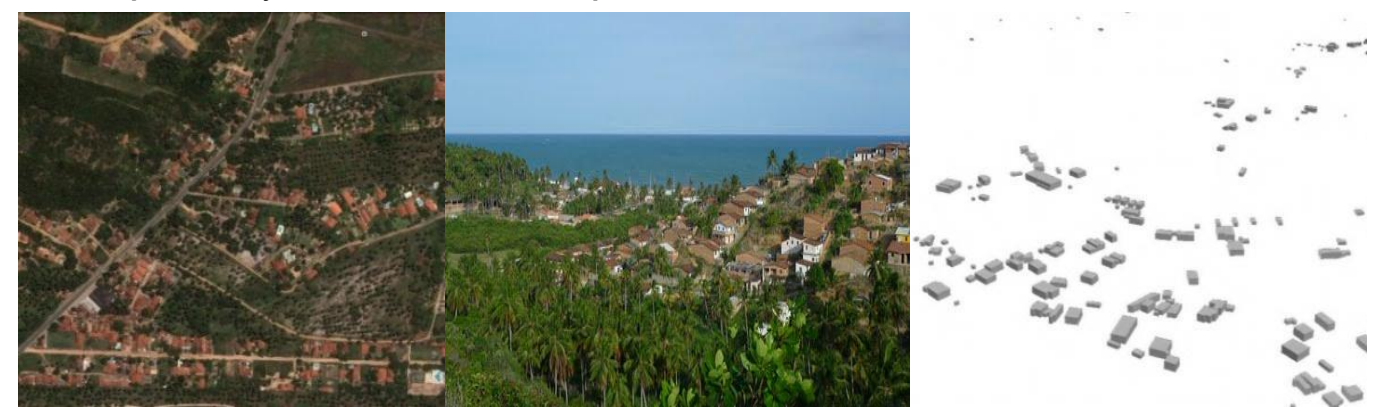

Fonte: Google Earth (2012) e foto do autor em 2012. 


\section{Classe 2: vertical baixo}

A classe 2 cobre $9 \%$ do tecido urbano da cidade. Apresenta, entre outras tipologias, a habitação vertical coletiva de até 4 pavimentos. Essa tipologia está cada vez mais presente no espaço urbano das cidades brasileiras, a exemplo dos conjuntos surgidos sobretudo na década de 80 , como o conjunto José Tenório, no bairro da Serraria, em Maceió (Figura 9). A tipologia é voltada para população de média e baixa renda. Os conjuntos caracterizam-se pela ocupação de toda uma quadra ou de áreas ainda maiores, muitas vezes com arruamentos internos. Algumas vezes, são isolados por muros e/ou grades e vigiados por guaritas. Reúnem edificações verticais em forma de prismas regulares, apresentando compacidade média de 5,18 e contiguidade quase sempre nula.

Ao observar-se o tecido presente nessa classe tipológica, quando composta dos conjuntos residenciais coletivos, estes se encontram presos no tecido e rodeados por habitações individuais (mais ou menos compactas), representando uma classe que pode ser descrita por certa heterogeneidade. Percebe-se igualmente a presença de zonas de vegetação importantes em algumas áreas (Figura 12). As edificações nesta classe apresentam suas alturas, em média, de 9,11 m, e o espaçamento entre os edifícios é menos importante quando comparado ao da classe anterior.

\section{Classe 3: colonial/contínuo}

A classe 3 representa $32 \%$ da superfície urbana construída da cidade e corresponde, principalmente, aos bairros do centro comercial da cidade, centro histórico, entre outros (Figura 13). Essas regiões são compostas de imóveis que variam de 1 a 4 pavimentos com altura média de $6,30 \mathrm{~m}$. Com a compacidade média menos elevada entre as classes tipológicas identificadas $(3,86)$ e, complementarmente, com contiguidade ponderada mais expressiva, as edificações encontradas nessas regiões estão inseridas em tecidos pouco porosos, com espaçamentos bastante reduzidos entre os edifícios, na maioria das vezes geminados. Tanto o TO quanto a DC apresentam-se mais elevados nessa classe tipológica $(0,74$ e 2,38 respectivamente).

\section{Classe 4: vertical alto}

Classe composta principalmente de habitações situadas na orla marítima de Maceió, como as áreas construídas nos bairros da Ponta verde, Pajuçara, Jatiúca e Mangabeiras (Figura 14).

\section{Figura 12 - Representação de bairro situado predominantemente na classe 2}

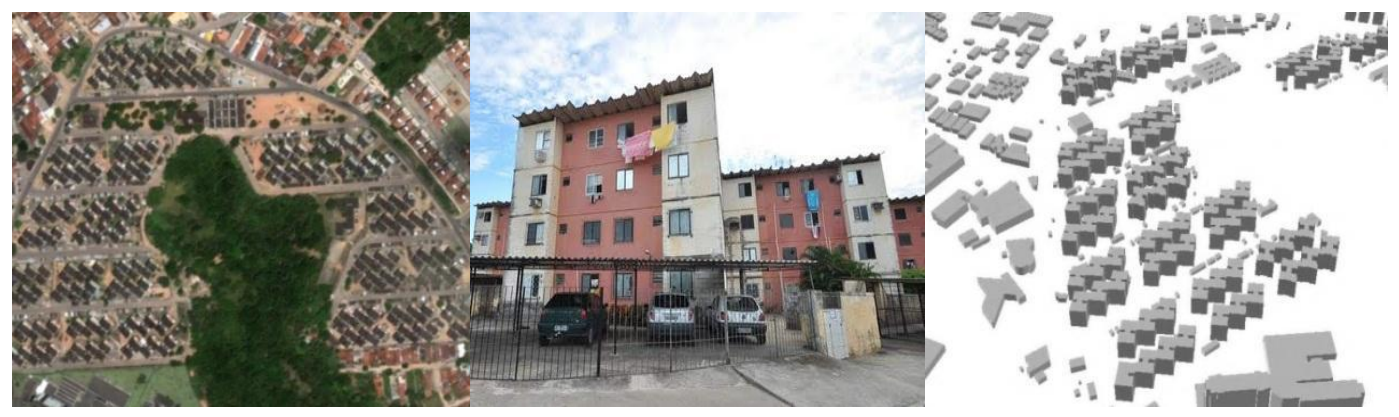

Fonte: Google Earth (2012) e foto do autor em 2012.

Figura 13 - Representação de bairro situado predominantemente na classe 3

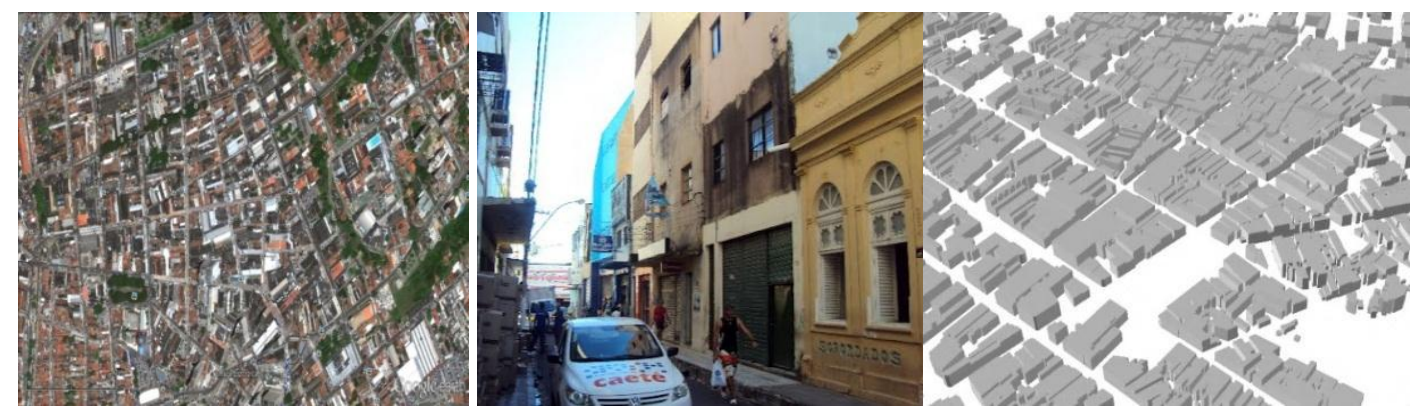

Fonte: Google Earth (2012) e foto do autor em 2012. 
Figura 14 - Representação de bairro situado predominantemente na classe 4
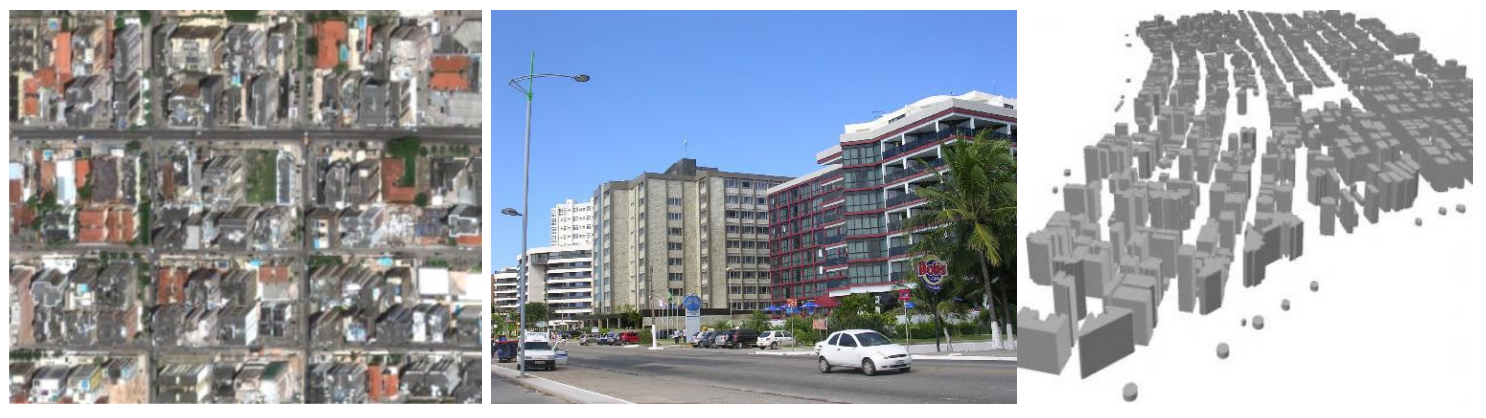

Fonte: Google Earth (2012) e foto do autor em 2012.

Esta classe é mais heterogênea que as anteriores, onde as formas e a altura podem variar (desvio padrão da altura média de 9,28 m), haja vista a presença ainda importante de edificações individuais baixas, que comportam outro tipo de forma. Mesmo vivenciando um progressivo processo de verticalização, essa classe tipológica compreende apenas cerca de $3 \%$ do tecido da cidade.

Apesar da elevada densidade total construída (DC de 4,15) e em virtude de um controle regulamentar mais importante nesses bairros (gabarito controlado pela existência de recuos progressivos, possibilitando afastamentos mais expressivos entre as edificações), apresenta-se como um tecido de porosidade importante. Em função dos recuos, a compacidade é elevada $(4,94)$, e a contiguidade, baixa, de 0,036.

\section{Classe 5: horizontal denso}

Classe composta, predominantemente, de habitat individual denso. Apresenta caráter bastante homogêneo, com poucas variações, que, por vezes, podem ser expressas nos volumes construídos de edificações que apresentam até 2 pavimentos (altura média de 5,18 m).

A classe 5 cobre cerca de $19 \%$ da malha urbana de Maceió. Em virtude de sua baixa compacidade $(3,66)$ e elevada contiguidade $(0,24)$, de um lado, revela-se uma importante densidade construída e, de outro, edificações de volumes relativamente reduzidos, com poucas fachadas e aberturas voltadas para o exterior, o que pode comprometer a qualidade interna dos espaços. É possível citar as áreas construídas que se situam nos bairros do Vergel do Lago, Trapiche da Barra, Levada, entre outros (Figura 15).

Quanto à relação entre as áreas construídas e os vazios, essas zonas apresentam morfologia de baixa porosidade e elevada rugosidade $(0,7$ e 2,37 respectivamente).

\section{Demanda de energia das estruturas urbanas}

Para a análise dos resultados obtidos pela simulação dinâmica do balanço de energia dos modelos urbanos, as demandas de energia foram divididas pela área total construída de cada classe tipológica considerada, a fim de obter-se um consumo estimado por metro quadrado habitável. Os resultados puderam, então, ser comparados a alguns parâmetros principais de forma e densidade. Tem-se assim a demanda de energia por classe, conforme a Tabela 8 e Figura 16.

Analisando-se os resultados obtidos, três parâmetros de forma podem ser citados como mais sensíveis à resposta do comportamento energético das classes tipológicas de Maceió: entre os indicadores de densidade, o DC e a verticalidade, a compacidade e o prospecto médio.

A menor demanda estimada por metro quadrado correspondeu à classe mais adensada entre as classes analisadas (classe 4) (Figura 17). O fator da verticalidade nessa área da cidade eleva o volume construído e proporcionalmente a área de envoltória exterior, elevando a compacidade dessa forma. Porém, essa demanda é bastante minimizada se observada a área total habitável. Apesar de caracterizada como uma das mais porosas classes tipológicas (em função dos afastamentos entre os edifícios), a relação dos afastamentos e a altura média dos edifícios podem gerar prospectos também elevados, fatores esses que permitem uma redução importante da fração visível do céu e um maior sombreamento das fachadas, reduzindo os ganhos de calor por radiação e, consequentemente, a carga estimada para resfriamento. Porém, ressalva-se que o aumento do prospecto pode também produzir uma redução importante de iluminação natural (dependendo da orientação da rua). 
Figura 15 - Representação de bairro situado predominantemente na classe 5

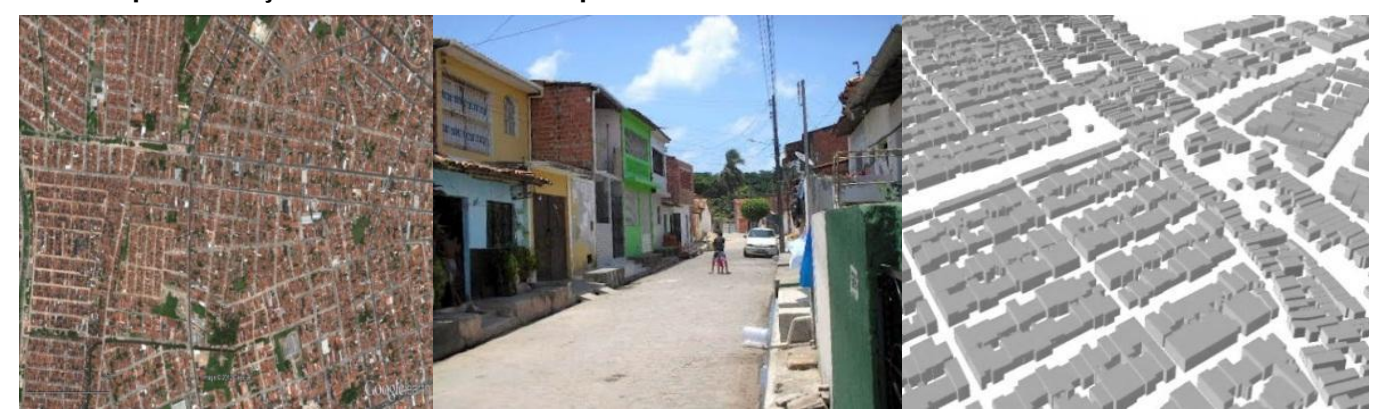

Fonte: Google Earth (2012) e foto do autor em 2012.

Tabela 8 - Demanda energética estimada por classe tipológica de referência

\begin{tabular}{l|c|c|c|c|c}
\hline \multicolumn{1}{c|}{ Média na classe } & $\mathbf{1}$ & $\mathbf{2}$ & $\mathbf{3}$ & $\mathbf{4}$ & $\mathbf{5}$ \\
\hline Demanda estimada (GWh) & 4782,7 & 17425,5 & 49411,9 & 50363,3 & 31241,9 \\
\hline Demanda estimada (MWh/m²/ano) & 869,30 & 314,86 & 332,01 & 193,83 & 661,83 \\
\hline Densidade construída & 0,08 & 0,88 & 2,38 & 4,15 & 0,75 \\
Compacidade & 4,75 & 5,18 & 3,87 & 4,94 & 3,66 \\
Vertocalidade & 0,33 & 0,89 & 0,70 & 1,72 & 0,39 \\
Prospecto médio & - & 0,90 & 0,40 & 1,25 & 0,46 \\
\hline
\end{tabular}

Figura 16 - Demanda energética estimada por classe tipológica de referência

Demanda estimada por classe tipológica

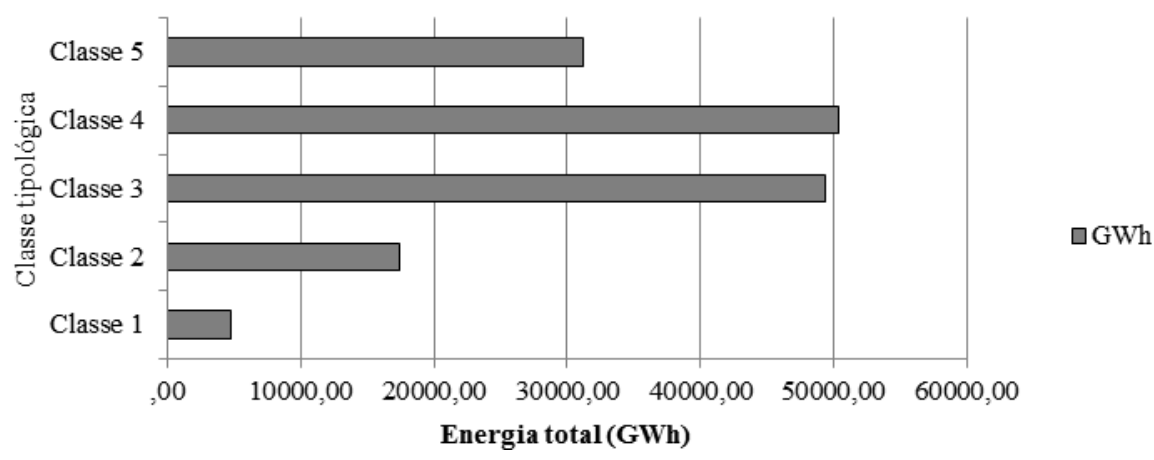

Figura 17 - Demanda energética estimada por metro quadrado por classe tipológica de referência Demanda estimada por $\mathrm{m} 2$ por classe tipológica

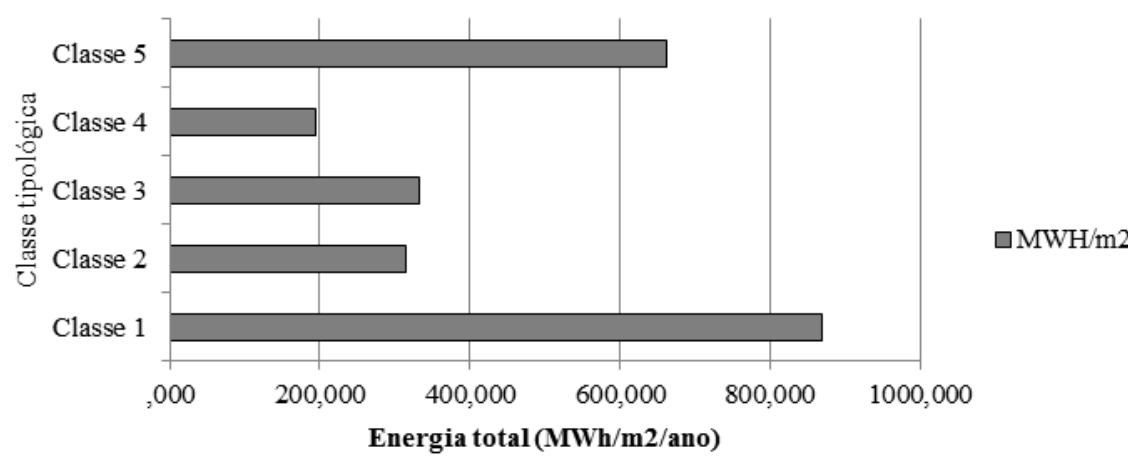

230 Martins, T. A. de L.; Bonhomme, M.; Adolphe, L. 
A classe menos eficiente correspondeu à menos adensada, de maior compacidade e maior prospecto construído (Classe 1). Essa forma pode não apenas ser desfavorável do ponto de vista da eficiência energética dos edifícios, mas pode também produzir um impacto importante no conforto térmico do pedestre, visto a redução de áreas sombreadas.

Comparando-se habitações individuais horizontais (presentes nas classes 1 e 5) em meio urbano disperso e meio urbano compacto, as habitações geminadas ou semigeminadas no contexto compacto podem consumir até $76 \%$ menos quando comparadas às habitações dispersas.

Para climas como o de Maceió, observa-se, portanto, o importante efeito induzido pela verticalização e adensamento do solo urbano na redução da demanda energética por metro quadrado dos edifícios. Comparando o impacto entre as classes mais densas e de menor demanda energética por metro quadrado (classes 3 e 4), observa-se entre estas ainda uma diferença de $58 \%$ na demanda das habitações coloniais quando comparadas às edificações verticais e de maior prospecto médio.

Ressalta-se que este trabalho apresenta-se como uma primeira aproximação na tentativa de qualificar e quantificar o impacto da forma urbana na demanda de energia dos edifícios. A resolução espacial considerada neste trabalho (microescala urbana) não permite considerar aspectos que possam apresentar-se determinantes no bom ou mau desempenho térmico e energético na escala do edifício, tais como o perfil de ocupação, presença de dispositivos de proteção solar, cargas internas ou sistemas mais sofisticados de climatização artificial, assim como os efeitos em escala maior (mesoescala urbana).

\section{Conclusões}

O estudo das modificações do solo urbano e do desenvolvimento adequado dos espaços construídos nas cidades passa pela necessidade premente de um conjunto de dados de base mais precisos e métodos apropriados para análise, compatíveis com a modelagem e interpretação da dinâmica dos complexos fenômenos urbanos.

O método proposto mostrou a capacidade de extrair, automaticamente, a partir de uma base de dados vetoriais urbanos, um mapeamento de áreas morfologicamente homogêneas, conforme indicadores ambientais de forma e densidade construída. E, a partir de uma classificação estatística, prever o desempenho energético da forma urbana de recortes espaciais representativos da cidade de Maceió.

Ressalta-se que outros fatores que se encontram fora do escopo deste trabalho (tais como a presença de vegetação e proximidade do mar e da lagoa) também possuem peso importante no balanço de energia do clima local e não são desprezíveis para o caso de Maceió, podendo ser explorados em trabalhos futuros.

A aplicação de modelos numéricos na escala urbana requer, ao mesmo tempo, certo grau de precisão, simplicidade e disponibilidade de banco de dados existente. Acredita-se, portanto, que os indicadores simplificados da morfologia urbana possam subsidiar de modo operacional o processo de decisão e planejamento das cidades, possibilitando a consideração dos principais fatores que definem o desempenho ambiental dos espaços construídos.

\section{Referências}

\section{ADENE. Eficiência Energética dos Edifícios \\ Residenciais. Lisboa, 2008. Disponível em: $<$ http://www.adene.pt/pt- \\ pt/Actividades/Documents/EE_EdRes_enerbuildin g.pdf>. Acesso em: 22 out. 2012.}

ADOLPHE, L. A Simplified Model of Urban Morphology: application to an analysis of the environmental performance of cities.

Environment and Planning B: Planning and Design, v. 28, n. 2, p. 183-200, 2001.

ADOLPHE, L. et al. SAGACités: systeme d'aide a la gestion des ambiances urbaines. Relatório final. MENRT, Action Concertée Incitative Ville, Toulouse, 2002.

ALBERTI, M.; WADDELL, P. An Integrated Urban Development and Ecological Simulation Model. Integrated Assessment, v. 1, n. 3, p. 215227, 2000.

\section{ALENCAR, B. J. A análise Multivariada Aplicada ao Tratamento da Informação} Espacial: uma abordagem matemáticocomputacional em análise de agrupamentos e análise de componentes principais. $200 \mathrm{f}$. Belo Horizonte, 2009. Tese (Doutorado em Geografia) Programa de Pós-Graduação em Geografia, Pontifícia Universidade Católica de Minas Gerais, Belo Horizonte, 2009. 
ALMEIDA, E.; BARBIRATO, G. M. A

Morfologia Urbana Como Determinante de Variações Climáticas Locais: estudo comparativo das orlas marítima e lagunar de Maceió - AL. In: ENCONTRO NACIONAL DE TECNOLOGIA DO AMBIENTE CONSTRUÍDO, 10., São Paulo, 2004. Anais... São Paulo: ENTAC, 2004.

AMORIM, L.; BARROS FILHO, M. N.; CRUZ, D. Urban Texture and Space Configuration Analysing Recife's Urban Fragments. In: INTERNATIONAL SPACE SYNTAX SYMPOSIUM, 7., Stockholm, 2009. Proceedings... Stockholm: KTH, 2009.

APUR. Consommations d'Énergie et Émissions de Gaz à Effet de Serre Liées au Chauffage des Résidences Principales Parisiennes. Paris: Atelier Parisien d'Urbanisme, 2007.

BATTY, M.; LONGLEY, P. Fractal Cities: a geometry of form and function. London: Academic Press, 1994.

BONHOMME, M.; ADOLPHE, L.; AITHADDOU, H. The Block-Generator: a tool for classification and evolution of urban typologies to assess environmental performances at the city scale. In: CONFERENCE ON PASSIVE AND LOW ENERGY ARCHITECTURE, 28., Lima, 2012. Proceedings... Lima, Peru: PLEA, 2012.

CARLO, J. C.; LAMBERTS, R. Parâmetros e Métodos Adotados no Regulamento de Etiquetagem da Eficiência Energética de Edifícios: parte 1: método prescritivo. Ambiente

Construído, Porto Alegre, v. 10, n. 2, p. 7-26, jul./set. 2010.

CATTELL, R. B. The Screen Test For the Number of Factors. Multivariate Behavioral Research, $n$. 1, n. 2, p. 245-276, 1966.

CIONCO R. M.; ELLEFSEN R. High Resolution Urban Morphology Data For Urban Wind Flow Modeling. Atmospheric Environment, v. 32, n. 1, p. 7-17, 1998.

CLARK, J. A. Energy Simulation in Building Design. 2. ed. Butterworth Heineman: Oxford, 2001.

DIDAY, E. et al. Eléments d'Analyse de Données. Paris: Dunod-Bordas, 1982.

GOMES, P. S.; LAMBERTS, R. O Estudo do Clima Urbano e Legislação Urbanística: considerações a partir do caso Montes Claros, MG. Ambiente Construído, Porto Alegre, v. 9, n. 1, p. 73-91, jan./mar. 2009.

GOOGLE EARTH. [Imagens]. Disponível em: <http://www.google.com/earth/>. Acesso em: 15 nov. 2012.
HEROLD, M.; COUCLELIS, H.; CLARKE, K. C. The Role of Spatial Metrics in the Analysis and Modeling of Urban Land Use Change.

Computers, Environments and Urban systems, v. 29, n. 4, p. 369-399, 2005.

HUANG, J.; LUB, X.; SELLERS, J. M. A Global Comparative Analysis of Urban Form: applying spatial metrics and remote sensing. Landscape and Urban Planning, v. 82, p. 184-197, 2007.

INSTITUO BRASILEIRO DE GEOGRAFIA E ESTATÍSTICA. Censo Demográfico 2010: características da população e dos domicílios, resultados do universo. Rio de Janeiro: IBGE, 2010. 270 p.

KAMPF, J. On the Modelling and Optimisation of Urban Energy Fluxes. 185 f. Lausanne, 2009. Tese (Doutorado em Meio Ambiente) - Faculté Environnement Naturel, Architectural et Construit, Ecole Polytechnique Fédérale de Lausanne. Lausanne, 2009.

LIMA, H. G.; ASSIS, E. A. Building Mass Calculation Using GIS Software For Climate Responsible Urban Planning Applications. In: CONFERENCE ON PASSIVE AND LOW ENERGY ARCHITECTURE, 20., Santiago, 2003. Proceedings... Santiago, Chile: PLEA, 2003.

MENDONÇA, R. S. R.; ASSIS, E. S. Conforto Térmico Urbano: estudo de caso do bairro Floresta, Belo Horizonte. Ambiente Construído, Porto Alegre, v. 3, n. 3, p. 45-63, out./dez. 2003.

NIELSEN, T. R. Simple Tool to Evaluate Energy Demand and Indoor Environment in the Early Stages of Building Design. Solar Energy, v. 78, n. 1, p. 73-83, 2005.

PEREZ, R.; SEALS, R.; MICHALSKY, J. All Weather Model For Sky Luminance DistributionPreliminary Configuration and Validation. Solar Energy, v. 50, n. 3, p. 235-243, 1993.

ROBINSON, D.; STONE, A. A Simplified Radiosity Algorithm For General Urban Radiation Exchange. Building Services Engineering Research and Technology, v. 26, n. 4, p. 271284, 2004.

ROBINSON, D. Computer Modeling For Sustainable Urban Design: physical principles, methods and applications. Londres: Earthscan, 2011.

ROUSSEAUX, F.; LONG, N.; RENOUARD, A. Vers Une Simulation de l'Évolution des Structures Urbaines à Partir d'Une Modélisation MultiAgents. Vertigo, v. 11, n. 3, dez. 2011.

SALAT, S. Les Villes et les Formes: sur l'urbanisme durable. Paris: Hermann, 2011. 
SEPLANDE. Dados Vetoriais Urbanos e Mapas Para a Cidade de Maceió e Estado de Alagoas. Secretaria de Estado do Planejamento e Desenvolvimento Econômico. Maceió, 2012. Arquivo digital.

SOUZA, L. C. L. et al. Fator de Visão do Céu e Intensidade de Ilhas de Calor na Escala do Pedestre. Ambiente Construído, Porto Alegre, v. 10, n. 4, p. 103-117, out./dez. 2010.

STEWART, I.D.; OKE, T. R. Newly Developed "Thermal Climate Zones" For Defining and Measuring Urban Heat Island Magnitude in the Canopy Layer. In: SYMPOSIUM ON THE URBAN ENVIRONMENT, 8., Phoenix, 2009. Proceedings... Phoenix: URBAN, 2009.
THEURER, W. Typical Building Arrangements For Urban Air Pollution Modeling. Atmospheric Environment, v. 33, p. 4057-4066, 1999.

TREGENZA P.; SHARPLES S. Daylighting Algorithms. ETSU Report S1350, Sheffield, UK: University of Sheffield, 1993.

WARD LARSEN, G.; SHAKESPEARE, R. Rendering With Radiance: the art and science of lighting visualization. São Francisco: Morgan Kauffmann, 1997.

\section{Agradecimentos}

Os autores agradecem à CAPES e ao CNPq, pelo auxílio financeiro concedido ao longo do desenvolvimento desta pesquisa.

Tathiane Agra de Lemos Martins

Programa de Pós-graduação em Arquitetura, Faculdade de Arquitetura e Urbanismo | Universidade Federal do Rio de Janeiro | Rua dos Ipês, s/n, Prédio da Reitoria, sala 433, Cidade Universitária | Rio de Janeiro - RJ - Brasil | CEP 21941-901 | Tel.: + 55 (21) 2598-1661| E-mail: tathianemartins@gmail.com

Marion Bonhomme

Laboratoire de Recherche en Architecture | Ecole Nationale Supérieure d'Architecture de Toulouse | 83 rue Aristide Maillol | BP 10629 | 31106 | Toulouse cedex 1 - France | Tel.: +33(0) 5 6211-5050 | E-mail: marion.bonhomme@toulouse.archi.fr

Luc Adolphe

Département Génie Civil et urbanisme | Institut National des Sciences Appliquées de Toulouse | 135 Avenue de Rangueil | Toulouse - França | CEP 31400| Tel.: +33(0) 685679585 | E-mail: luc.adolphe@gmail.com

\section{Revista Ambiente Construído}

Associação Nacional de Tecnologia do Ambiente Construído

Av. Osvaldo Aranha, $99-3^{\circ}$ andar, Centro

Porto Alegre - RS - Brasil

CEP $90035-190$

Telefone: +55 (51) 3308-4084

Fax: +55 (51) 3308-4054

www.seer.ufrgs.br/ambienteconstruido

E-mail: ambienteconstruido@ufrgs.br 